\title{
The protein modifier SUMO is critical for Arabidopsis shoot meristem maintenance at warmer ambient temperatures
}

\section{Authors:}

Valentin Hammoudi ${ }^{1 *}$, vhammoudi@zedat.fu-berlin.de

Bas Beerens $^{1 *}$, b.beersens@uva.nl

Martijs J. Jonker ${ }^{2}$, m.j.jonker@uva.nl

Tieme A. Helderman ${ }^{1}$, t.a.helderman@uva.nl

Georgios Vlachakis ${ }^{1}$, georgios@sparkgenetics.com

Marcel Giesbers ${ }^{3}$, marcel.giesbers@wur.nl

Mark Kwaaitaal ${ }^{1}$, mark.kwaaitaal@gmail.com

Harrold A. van den Burg ${ }^{1, \S}$, h.a.vandenburg@uva.nl, Phone: +31 (0)20 5257797

*, contributed equally to this work;

$\S$, Corresponding author

\section{Affiliations}

${ }^{1}$ Molecular Plant Pathology, Swammerdam Institute for Life Sciences, University of Amsterdam, The Netherlands

${ }^{2}$ RNA Biology and Applied Bioinformatics, Swammerdam Institute for Life Sciences, University of Amsterdam, The Netherlands

${ }^{3}$ Wageningen Electron Microscopy Centre, Wageningen University, The Netherlands

\section{Running title}

Plant meristem thermo-resilience depends on SUMO

Date of submission: 11-01-2021

Number of Tables: 0

Number of Figures: 7

Total word count: $\quad 5476$ [introduction-acknowledgement w/o M\&M] 


\section{Highlight:}

The protein modifier SUMO governs shoot meristem maintenance in Arabidopsis allowing sustained rosette development when plants endure a sustained warm nondetrimental period of 28 degrees Celsius.

\section{Abstract}

Short heat waves $\left(>37^{\circ} \mathrm{C}\right)$ are extremely damaging to non-acclimated plants and their capacity to recover from heat stress is key for their survival. To acclimate, the HEAT SHOCK TRANSCRIPTION FACTOR A1 (HSFA1) subfamily activates a transcriptional response that resolves incurred damages. In contrast, little is known how plants acclimate to sustained non-detrimental warm periods at $27-28^{\circ} \mathrm{C}$. Plants respond to this condition with a thermomorphogenesis response. In addition, HSFA1 is critical for plant survival during these warm periods. We find that SUMO, a protein modification whose conjugate levels rise sharply during acute heat stress in eukaryotes, is critical too for plant longevity during warm periods, in particular for normal shoot meristem development. The known SUMO ligases were not essential to endure these warm periods, alone or in combination. Thermo-lethality was also not seen when plants lacked certain SUMO proteases or when SUMO chain formation was blocked. The SUMO-dependent thermo-resilience was as well independent of the autoimmune phenotype of the SUMO mutants. As acquired thermotolerance was normal in the sumo1/2 knockdown mutant, our data thus reveal a role for SUMO in heat acclimation that differs from HSFA1 and SIZ1. We conclude that SUMO is critical for shoot meristem integrity during warm periods.

\section{Key words}

Acclimation, growth recovery, heat shock, meristem, protein modification, rosette development, SUMO, sumoylation, thermo-resilience

\section{Abbreviations}

DEG, differentially expressed gene; GO, gene ontology; HSF, Heat Shock transcription Factors; HSP, Heat Shock Protein; LAT/SAT, long/short-term acquired thermotolerance; $L D_{50}$, median lethal dose; PCA, principal component analysis; ROS, reactive oxygen species; SAM, Shoot apical meristem; SUMO, Small ubiquitin-like modifier; sumoylation, SUMO attachment to substrates. 


\section{Introduction}

2 Plants are constantly challenged by temperature fluctuations caused by day-night

3 cycles, weather conditions, seasonal shifts, climate extremes and global warming.

4 These fluctuations differ in temperature range, duration and gradient. Plants acclimate to the ambient temperature via an intertwined molecular network that resolves the (protein) damage incurred while changing their morphology and performance to better deal with temperature extremes (Dickinson et al., 2018; Ding et al., 2020). Heat extremes cause among others protein unfolding, membrane damage, and release of reactive oxygen species (ROS) (Hightower, 1991). Heat-inflicted damage is perceived via Heat Shock transcription Factors (HSFs) that up-regulate expression of Heat Shock Proteins (HSPs) and other protein-folding chaperones (Wu, 1995). The misfolded proteins are then stabilized and refolding by HSPs and, when ineffective, HSPs target misfolded proteins for degradation (Wang et al., 2004). In particular, HSP70 and HSP90 are central players for resolving protein damage, while HSP101 is critical for short- and long-term acquired thermotolerance (SAT and LAT) (Hong and Vierling, 2001; Queitsch et al., 2000).

In Arabidopsis (Arabidopsis thaliana) heat stress is perceived by the four members of the HSF clade A1 (HSFA1) (Liu and Charng, 2013; Liu et al., 2011; Ohama et al., 2016). Prior to heat stress, HSFA1 is kept in an inactive state in the cytoplasm by HSP70 and HSP90 (Ohama et al., 2016; Yoshida et al., 2011). Upon heat stress, HSFA1 shuttles to the nucleus where it induces expression of heatresponsive genes including genes encoding additional transcription factors (HSFA2, DREB2A (DEHYDRATION RESPONSIVE ELEMENT BINDING 2A), DREB2B, and MBF1C (MULTIPROTEIN BRIDGING FACTOR 1C). Combined these gene products form a second transcriptional wave that orchestrates the stress response while promoting plant acclimation to a subsequent heat wave (Kotak et al., 2007; Liu et al., 2011; Nishizawa-Yokoi et al., 2011; Yoshida et al., 2011). Overall, HSFA1 is regarded to be the master regulator of heat stress in plants. HSFA1 plays also a role in cold acclimation via NPR1 (NON-EXPRESSER OF PATHOGENESIS-RELATED GENES 1), which is a master regulator of the plant response to biotrophic pathogens (Olate et al., 2018).

Importantly, protein modifications play as well an important regulatory role in response to heat stress, in particular sumoylation. Many proteins are for example 
acute heat stress (Golebiowski et al., 2009; Miller et al., 2010; Miller et al., 2013; Miller and Vierstra, 2011; Tatham et al., 2011). One mechanism is that sumoylation promotes the solubility of proteins during heat stress in mammalian cells (Liebelt et al., 2019). In human cells sumoylation also controls the transcriptional response to heat stress by modifying the transcription factor HSF1, the closest homolog of Arabidopsis HSFA1 (Hietakangas et al., 2003; Hilgarth et al., 2003; Hong et al., 2001). Also for Arabidopsis evidence exists that the HSF regulatory pathway is subject to sumoylation. For instance, the transcription factors HSFA1b, HSFA1d, HSFA2 and DREB2A are sumoylated in planta (Augustine and Vierstra, 2018; Miller et al., 2010; Miller et al., 2013; Rytz et al., 2018), but the role of SUMO in (a) acute heat stress and (b) acclimation to sustained warm periods remains poorly understood in plants. SUMO conjugate levels increase sharply in Arabidopsis in response to heat stress affecting hundreds of targets (Miller et al., 2013; Rytz et al., 2018). This global increase depends strongly on the SUMO E3 ligase SIZ1 (SAP AND MIZ-FINGER DOMAIN 1) and is attenuated in plants overexpressing HSP70 (Kurepa et al., 2003; Miller et al., 2013; Rytz et al., 2018; Yoo et al., 2006). The latter implies that heat stress triggers a global increase in SUMO conjugate levels that is connected to protein damage via an unknown mechanism and with an unknown impact on plant development and stress acclimatization. Studies with mammalian cells have suggested that acute heat stress causes inactivation of certain SUMO proteases, which would explain the sudden increase in SUMO adducts (Liebelt et al., 2019; Pinto et al., 2012).

In contrast to heat stress, sustained warm periods of $27-28^{\circ} \mathrm{C}$ do not lead to permanent protein damage in plants and they do not cause up-regulation of known heat stress marker genes (Kumar and Wigge, 2010). Instead, plants respond to warm temperatures by altering their development (called thermomorphogenesis), including early flowering, leaf hyponasty, hypocotyl stretching and petiole elongation. (Casal and Balasubramanian, 2019; Qiu et al., 2019; Quint et al., 2016). As a consequence, the rosette of Arabidopsis adopts an open architecture, which is supposed to increase the leaf cooling capacity. This thermomorphogenesis response depends as well on SIZ1 activity and the two main SUMO isoforms, SUMO1 and -2 (Hammoudi et al., 2018). 
All our studies with the SUMO1/2 knockdown mutant (sumo1-1;35S Pro::amiRSUMO2, hereafter sumo1/2KD) have thus far indicated that it closely resembles the phenotype of siz1 loss-of-function mutants, including (i) high levels of the defense hormone salicylic acid (SA), (ii) constitutive expression of PATHOGENESISRELATED PROTEINS 1 and -2 (PR1 and PR2), (iii) spontaneous cell death, (iv) dwarf stature with curled leaves, ( $v$ ) early flowering, (vi) loss of apical dominance, but also (vii) compromised thermo- and photomorphogenesis responses (Hammoudi et al., 2018; van den Burg et al., 2010). The autoimmune phenotype of siz1 is dependent on the immune receptor SNC1 (SUPPRESSOR OF NPR1-1, CONSTITUTIVE 1) (Gou et al., 2017). Normally, SNC1 autoimmunity is suppressed at $28^{\circ} \mathrm{C}$, resulting in a wild type rosette shape at this temperature (Yang and Hua, 2004; Zhu et al., 2010). Autoimmunity due to the siz1 mutation is, however, not suppressed at $28^{\circ} \mathrm{C}$ and correspondingly growth of siz1 rosettes is only partially recovered at $28^{\circ} \mathrm{C}$ (Hammoudi et al., 2018). This signifies that SIZ1-dependent SUMO conjugation inhibits SNC1 immune signaling, directly or indirectly, both at normal and warm temperatures.

We now report that SUMO1/2 combined are critical for sustained rosette development when plants endure periods of $28^{\circ} \mathrm{C}$. Interestingly, this role of SUMO1/2 is highly reminiscent of the function of Arabidopsis HSFA1 at this temperature (Liu and Charng, 2013; Liu et al., 2011). Yet the HSFA1 response appears to be intact the sumo1/2 ${ }^{K D}$ mutant. Moreover, the SUMO protein levels are critical for rosette development and shoot meristem integrity at $28^{\circ} \mathrm{C}$ independent of SIZ1 and HPY2, the two main SUMO E3 ligases in Arabidopsis. This role of SUMO in thermoresilience did also not depend on immune signaling. We thus report a novel role for SUMO in plant thermo-resilience.

\section{Materials and methods}

\section{Plant materials and growth conditions}

Arabidopsis thaliana (L.) Heynh was used for the experimentation with the mutants and transgenic lines as detailed in the Supplementary Table S1. All lines were obtained from Nottingham Arabidopsis Stock Centre (NASC) or from the sources listed in the Supplementary Table S1. To obtain additional sumo1-1;35S Pro::amiR- 
100 SUMO2 lines (sumo1/2KD), independent 35S Pro::amiR-SUMO2 (T1) lines were

101 screened for low SUMO2 expression using real time RT-PCR. Four additional lines

102 with low SUMO2 expression levels were identified and they were crossed with

103 sumo1-1;sumo3-1. After crossing of sumo1/2KD line B with pad4-1, sid2-1 or eds1-2

104 with, the F2 progeny was genotyped for the alleles SUMO1, sumo1-1, amiR-SUMO2

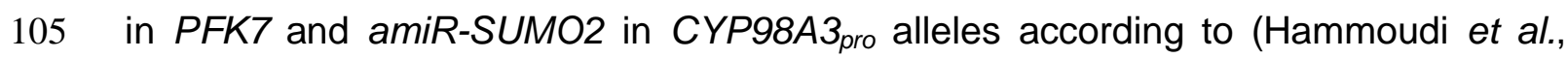

106 2017). Primers and genotyping details are given in Supplementary Table S2 and

107 S3, respectively.

108 Arabidopsis plants were grown under short day conditions (11 h light/13 h

109 dark) at a constant temperature of $22^{\circ} \mathrm{C}$ or $28^{\circ} \mathrm{C}$ unless specified otherwise. When

110 grown on plates, seeds were gas-sterilised, stratified in liquid for 2 or 3 days at $4{ }^{\circ} \mathrm{C}$

111 in the dark conditions and then germinated on $0.5 \mathrm{x}$ Murashige and Skoog salt

112 mixture with Gamborg B5 vitamins (Duchefa), $0.5 \mathrm{~g}$ MES (Duchefa), $0.1 \mathrm{~g}$ Myo-

113 Inositol (Merck) and 0.8 or $1 \%$ Daishin agar (Duchefa) pH 5.7, with the same light

114 regime at $22{ }^{\circ} \mathrm{C}$. To induce proteotoxic or abiotic stress, the plates were

115 supplemented with L-Canavanine $(10 \mu \mathrm{M})$, mannitol $(300 \mathrm{mM})$, or $\mathrm{NaCl}(75 \mathrm{mM})$.

116 Heat stress treatments were performed as previously described (Liu and Charng,

117 2013). Briefly, for short-term acquired thermotolerance (SAT) 7-day-old seedlings

118 were acclimated at $37^{\circ} \mathrm{C}$ for $60 \mathrm{~min}$ and then allowed to recover for $120 \mathrm{~min}$ at $22^{\circ} \mathrm{C}$

119 before being incubated at a noxious temperature of $44^{\circ} \mathrm{C}$ for $90 \mathrm{~min}$. For long-term

120 acquired thermotolerance (LAT), 7-day-old seedlings were acclimated at $37^{\circ} \mathrm{C}$ for 60

$121 \mathrm{~min}$, then recovered for two days at $22^{\circ} \mathrm{C}$ before being incubated at $44^{\circ} \mathrm{C}$ for $50 \mathrm{~min}$.

\section{Gene expression quantification}

124 For the gene expression analysis, total RNA was isolated using TRIzol Reagent 125 (ThermoFisher) according to the suppliers' instructions. A total of $2 \mu \mathrm{g}$ RNA was used 126 for cDNA synthesis using Superscript III (ThermoFisher). RNAse activity was 127 inhibited by adding RiboLock (ThermoFisher) during cDNA synthesis. Real-time PCR 128 was performed on an ABI 7500 real-time PCR system (Applied Biosystems). Primers 129 used for the gene expression analysis are given in Supplementary Table S2. The 130 cycling program was set to $2 \mathrm{~min}, 50^{\circ} \mathrm{C} ; 10 \mathrm{~min}, 95^{\circ} \mathrm{C} ; 40$ cycles of $15 \mathrm{~s}$ at $95^{\circ} \mathrm{C}$; and $1311 \mathrm{~min}, 60^{\circ} \mathrm{C}$, and a melting curve analysis was performed at the end of the PCR. All 132 primer pairs were tested for specificity and for amplification efficiency using a two-fold 
133 dilution series of a mixed cDNA sample. The biological samples were normalized

134 against three housekeeping genes (Czechowski et al., 2005) using geometric

135 averaging: ACT2 (At3g18780), UBQ10 (At4g05320), and UBC21 (At5g25760).

136 Primers used were described previously (Czechowski et al., 2005) (Supplementary

137 Table S2). The data were analysed using the methods included in the gene 138 expression software qBASE+ (BioGazelle, Belgium) with a correction for the

139 amplification efficiencies of the primer pairs.

\section{Protein analysis}

142 For the heat shock treatments, Arabidopsis seedlings were pre-grown on plates (half-

143 strength Murashige and Skoog salt mixture supplemented with Gamborg B5

144 vitamins) for 14 days under SD light conditions at $22^{\circ} \mathrm{C}$. Seedlings were exposed to a

14530 -minute acute heat shock at $37^{\circ} \mathrm{C}$ in the dark and left to recover at $22^{\circ} \mathrm{C}$ for $60 \mathrm{~min}$

146 before freezing the samples in liquid nitrogen for storage at $-80^{\circ} \mathrm{C}$ untill total protein

147 extraction (Kurepa et al., 2003). The total protein fraction was extracted by

148 homogenizing the frozen plant material with metal beads (2.5 $\mathrm{mm}$ diameter) in a

149 TissueLyser II (Qiagen). Per fresh sample weight, two volumes of a freshly prepared

150 Protein extraction (PE) buffer (50 mM potassium phosphate buffer pH 7.0, $150 \mathrm{mM}$

$151 \mathrm{NaCl}, 1 \mathrm{mM}$ EDTA, 2\% (w/v) poly(vinylpolypyrrolidone), 1× cOmplete mini EDTA-free

152 protease inhibitor cocktail (Roche), 1\% Nonidet P-40, 10\% (w/v) glycerol and either 5

153 mM DTT or 20 mM NEM) were added followed by mixing with a vortex for 10 sec.

154 The cell lysates were incubated for $15-30$ minutes $\left(4^{\circ} \mathrm{C}, 20 \mathrm{rpm}\right.$ on rotating wheel)

155 and then centrifugated for $10 \mathrm{~min}$ at $16,000 \mathrm{~g}\left(4^{\circ} \mathrm{C}\right)$. Total protein concentrations

156 were measured using a BCA protein assay kit (Sigma) and normalized when needed

157 by adding extra PE buffer. For denaturation, the protein extracts were mixed 1:1 with

$1582 \times$ Sample loading buffer (100 mM Tris- $\mathrm{HCl}$ pH 6.8, 4\% SDS, 20\% glycerol, and 100

$159 \mathrm{mM}$ DTT) and then boiled for $10 \mathrm{~min}$. The denatured protein samples $(20 \mu \mathrm{L})$ were

160 loaded on a 10-15\% SDS-PAGE gels, separated by electrophoresis, and then

161 transferred onto a polyvinylidene fluoride membrane (PVDF; Immobilon-P, Millipore)

162 using semi-dry blotting according to the suppliers' instructions (Hoefer). Equal protein

163 loading and transfer to the blot was confirmed by staining the PVDF membranes with

$1640.1 \%$ Ponceau S in 5\%(v/v) acetic acid. After destaining with two rinses of $5 \%(\mathrm{v} / \mathrm{v})$

165 acetic acid, the blot was scanned and further destained by rinsing them thrice with 
166 Tris Buffer Saline (TBS; $25 \mathrm{mM}$ Tris- $\mathrm{HCl} \mathrm{pH}$ 7.6, $137 \mathrm{mM} \mathrm{NaCl}$, and $2.7 \mathrm{mM} \mathrm{KCl}$ ).

167 The membranes were blocked with 5\% (w/v) skimmed milk powder dissolved in TBS

168 supplemented with $0.05 \% \mathrm{v} / \mathrm{v}$ Tween 20 (TBST). Incubations with both the primary

169 and secondary antibodies were performed in TBST supplemented with 5\% milk

170 powder, followed by three rinses of 5, 10 and 15 minutes with TBST (after the

171 primary antibody) or TBS (after the secondary antibody). The secondary

172 immunoglobulins conjugated to horseradish peroxidase were visualized using

173 enhanced chemiluminescence with a commercial kit (ECL Pierce Plus,

174 ThermoFisher) or a homemade solution $(100 \mathrm{mM}$ Tris- $\mathrm{HCl} \mathrm{pH} 8.5$, freshly

175 supplemented with $50 \mu \mathrm{L}$ of $250 \mathrm{mM}$ Luminol in DMSO, $22 \mu \mathrm{l}$ of $90 \mathrm{mM}$ coumaric

176 acid in DMSO, and $3 \mu \mathrm{l} 30 \% \mathrm{H}_{2} \mathrm{O}_{2}$ solution). The luminescence signals were detected

177 using MXBE Kodak films (Carestream). Details on the antibodies used are given in

178 the Supplementary Table S1.

Microarray gene expression analysis

181 Briefly, pad4-1, sumo1/2KD;pad4-1, siz1-2;pad4-1 and eTK plants were grown on soil 182 at $22^{\circ} \mathrm{C}$ in short day conditions for 2 weeks and then transferred to $28^{\circ} \mathrm{C}$. Leaf 183 samples were collected at moment of the shift to $28^{\circ} \mathrm{C}$ and after 24 or $96 \mathrm{~h}$ at $28^{\circ} \mathrm{C}$ 184 and used for RNA extraction using Trizol Reagent (ThermoFisher). Three biological 185 replicates were collected for each sample. Total RNA was further purified using the 186 RNAeasy Plant mini Kit (Qiagen). The RNA quality was examined by monitoring the 187 Absorbance ratios at 260/280 nm and 260/230 nm. A total of $100 \mathrm{ng}$ total RNA was 188 amplified using the GeneChip WT PLUS Reagent Kit (Affymetrix) to generate 189 biotinylated sense-strand DNA targets. The labeled samples were hybridized to 190 Affymetrix Arabidopsis Gene 1.1 ST arrays (ThermoFisher). Washing, staining and 191 scanning was performed using the GeneTitan Hybridization, Wash, and Stain kit for 192 WT Array Plates, and the GeneTitan instrument (Affymetrix). All arrays were 193 subjected to a set of quality control checks, such as visual inspection of the scans, 194 checking for spatial effects through pseudo-color plots, and inspection of pre- and 195 post-normalized data with box plots, ratio-intensity plots and principal component 196 analysis (PCA). Normalized expression values were calculated using the robust 197 multi-array average (RMA) algorithm (Irizarry et al., 2003). The experimental groups 198 were contrasted to test for differential gene expression. Statistical analysis was 
199 performed to test the experimental groups for differential gene expression compared

200 to pad4-1, at each time point. Empirical Bayes test statistics were used for

201 hypothesis testing (Smyth, 2004) using the Limma package in R 3.4.1 (http://cran.r-

202 project.org/), and all obtained $p$-values were corrected for false discoveries according

203 to Storey and Tibshirani (Storey and Tibshirani, 2003). The DEGs were selected

204 using an F-test in the Limma package, designed to test for differential expression

205 between any of the four genotypes (pad4-1, pad4-1;sumo1/2 ${ }^{K D}$; pad4-1;siz1-2; pad4-

2061 and $e T K$ plants) at the individual time points. An overall comparison of the gene

207 expression responses due to increase in ambient temperature between all genotypes

208 simultaneously was made by PCA. To interpret the PCA results, a gene ontology

209 (GO) analysis (on "biological processes" only) was performed on the top 500 genes

210 with the highest absolute loading scores for PC1 and PC2, respectively, using

211 AgriGOv2 (Tian et al., 2017). This PCA+GO comparison was also made based on

212 the genome wide response of (a) all measured genes and also based on the

213 transcriptome response of a collection of genes, selected using an F-test in the

214 Limma package, designed to test for differential expression between any of the four

215 groups. The AgriGOv2 results were plotted in R using clusterProfiler (Yu et al., 2012).

216 The p-values for the GO terms were calculated using a hypergeometry test with

217 Yekutieli FDR under dependency; q-value $\left(\mathrm{P}_{\mathrm{adj}}\right)<0.01$ using the complete $\mathrm{GO}$ as

218 implement in AgriGOv2. The dot plots displaying the significant GO terms for the

219 different PC axes were generated using the R package clusterProfiler ( $\mathrm{Yu}$ et al.,

220 2012). Absence of a dot signifies that GO terms is non-significant at that time point.

221

222 Cryo-scanning electron microscopy (cryo-SEM)

223 Excised apical meristems were attached to a sample holder using a very thin layer of

224 Tissue-Tek compound (EMS, Washington, PA, USA). Samples were plunge frozen in

225 liquid nitrogen and subsequently placed in a cryo-preparation chamber (MED

226 020/VCT 100, Leica, Vienna, Austria). To sublimate any water vapor contamination

227 (ice) from the surface, the samples were kept for 4 minutes at $-93^{\circ} \mathrm{C}$. Samples were

228 then sputter coated with a $12 \mathrm{~nm}$ layer of Tungsten (W), and transferred under

229 vacuum to the field emission scanning electron microscope (Magellan 400, FEl,

230 Eindhoven, the Netherlands) onto the sample stage at $-120^{\circ} \mathrm{C}$. The images were

231 taken with SE detection at $2 \mathrm{kV}, 13 \mathrm{pA}$. 


\section{Propidium iodide staining and imaging of roots}

234 Seeds were germinated for 4 days on vertical $0.5 \mathrm{x}$ MS plates at $22^{\circ} \mathrm{C}$. Seedlings that 235 germinated were transferred to new 0.5x MS plates and grown for another 8-10 days 236 at (i) $22^{\circ} \mathrm{C}$, (ii) $28^{\circ} \mathrm{C}$, or (iii) first placed at $22^{\circ} \mathrm{C}$ for 3 days and then shifted to $28^{\circ} \mathrm{C}$ for 237 another 5-7 days. These plates were scanned at 12 days post germination and the 238 main root length and number of lateral roots was measured in ImageJ (https://fiji.sc/) 239 for each sample. For confocal laser scanning microscopy (CLSM), the roots were 240 detached from the seedlings with a scalpel and transferred to a Propidium iodide (PI) 241 (ThermoFisher) staining solution (final concentration $10 \mu \mathrm{g} / \mathrm{ml}$, diluted from a $1 \mathrm{mg} / \mathrm{ml}$ 242 stock) in a 6-well plate. Roots were incubated for 5-10 min in the dark, rinsed in a 243 separate well with water, transferred to a microscopy slide and covered with a 244 coverslip. Imaging was performed using a Zeiss LSM 510 or Nikon A1 CLSM, using a 245 20x Plan-Apochromat lens with Numerical Aperture (NA) 0.75 or a 20x Plan Fluor 246 DIC N2 lens with an NA of 0.75 , respectively. PI was excited with a $561 \mathrm{~nm}$ diode 247 laser, thereafter the emission light was selected using a 600/30 nm or 595/50 nm 248 bandpass filter, respectively, before detection with photomultiplier tubes. 249 Simultaneously, a bright field image was recorded with the transmitted light detector.

\section{Quantification and Statistical analysis}

Data visualization and statistical analyses of the data were performed using the software PRISM (GraphPad). Statistical analyses and plots were computed in PRISM using built-in functions. Statistical information is further specified in the Figure captions.

\section{Results}

258 Previous work on sumo1/2KD exposed that its phenotype resembles the SUMO ligase 259 mutant siz1-2 (Hammoudi et al., 2018; van den Burg et al., 2010). While studying the 260 role of SUMO in thermomorphogenesis (Fig. 1A), we noted that development of 261 sumo $1 / 2^{K D}$ seedlings was arrested at $28^{\circ} \mathrm{C}$ resulting in their collapse 14 days post 262 germination. Opening of the cotyledons was still normal at this temperature, but 263 sumo $1 / 2^{K D}$ failed to develop new leaves. In contrast, at normal temperatures $\left(22^{\circ} \mathrm{C}\right)$ 264 new leaves formed, but they were curled and small. At $16^{\circ} \mathrm{C}$, leaf development of 
265 sumo $1 / 2^{K D}$ was similar to $22^{\circ} \mathrm{C}$ except that the rosette diameter doubled in size. A 266 similar cool-temperature response (i.e. increased rosette diameter at $16^{\circ} \mathrm{C}$ ) was seen

267 for two SNC1-dependent autoimmune mutants, srfr1-4 (suppressor of rps4-rld 4) and 268 bon1 (bonzai 1). This latter observation suggests that the cool temperature response 269 might be connected with unbalanced SNC1 signaling, while the high temperature 270 collapse clearly differs from the SNC1-dependent phenotype of siz1. At $25^{\circ} \mathrm{C}$ (Fig.

271 1A), sumo1/2 $2^{K D}$ seedlings survived even though their growth was suppressed 272 compared to $22^{\circ} \mathrm{C}$.

273 To exclude that SUMO-dependent thermo-resilience is an artefact of the plant 274 transformation procedure, we assessed thermo-resilience of the mutants sumo1-1, 275 sumo2-1, and 35S Pro::amiR-SUMO2 (line B). Each mutant withstood $28^{\circ} \mathrm{C}$ without 276 tissue collapse while also displaying a wildtype-like thermomorphogenesis response 277 as evidenced by the elongated petioles and leaf blades (Fig. 1B). Moreover, we 278 generated four independent crosses between sumo1-1 and plants with reduced 279 SUMO2 transcript levels due to expression of amiR-SUMO2 (lines P, S, V, and W). 280 None of the amiR-SUMO2 parental lines had an aberrant growth phenotype at $22^{\circ} \mathrm{C}$, 281 while plants with a typical sumo $1 / 2^{K D}$ morphology were present in the $\mathrm{F} 2$ progeny, i.e. 282 plants with a dwarf stature, curled leaves, lesions and premature flowering 283 (Supplementary Fig. S1A)(van den Burg et al., 2010). Genotyping of the dwarf plants confirmed they were homozygous for sumo1-1 and they contained (at least)

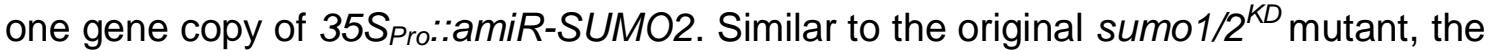
dwarf plants were thermo-sensitive resulting in their collapse after two weeks at $28^{\circ} \mathrm{C}$. Clearly, SUMO1/2 combined confer thermo-resilience at $28^{\circ} \mathrm{C}$.

Since the developmental phenotype of siz1 and sumo1/2KD is in part caused by autoimmunity and concomitantly high SA levels (Hammoudi et al., 2018; Lee et al., 2007; van den Burg et al., 2010), sumo1/2 ${ }^{K D}$ was crossed with mutants defective 291 in this immune response, i.e. pad4-1 (phytoalexin-deficient4-1), eds1-2 (enhanced 292 disease susceptibility1-2) and sid2-1 (salicylic acid induction deficient2-1). The 293 proteins PAD4 and EDS1 form together an immune hub, while SID2 encodes for the 294 enzyme ISOCHORISMATE SYNTHASE 1 (ICS1) needed for SA biosynthesis in 295 response to pathogen recognition. As expected, sumo1/2KD autoimmunity was 296 suppressed at $22^{\circ} \mathrm{C}$ in the backgrounds pad4, eds1 and sid2 (Fig. 1C). For example, 297 the levels of the defense marker proteins PR1 and PR2 were no longer elevated in 
298 the triple mutants sumo1/2 ${ }^{K D} ;$ pad4, sumo1/2 ${ }^{K D}$;eds1 and sumo1/2 ${ }^{K D}$;sid2 (Fig. 1C,

299 1D). Nonetheless, these triple mutants still collapsed when grown at $28^{\circ} \mathrm{C}$, while the

300 single mutants pad4, eds 1 and sid2 developed normally at $28^{\circ} \mathrm{C}$ (including a normal

301 thermomorphogenesis response). Thus, thermo-lethality of sumo1/2 ${ }^{K D}$ is independent

302 of its autoimmunity.

303 To assess whether other components of the SUMO (de)conjugation pathway

304 support sustained plant growth at $28^{\circ} \mathrm{C}$, different loss-of-function mutants were tested

305 including the isoform SUMO3, the SUMO E3 ligase HPY2/MMS21 (HIGH PLOIDY 2,

306 MMS21) and different SUMO proteases. As SUMO proteases, the role of ESD4

307 (EARLY IN SHORT DAYS 4) alone, OTS1/2 (OVERLY TOLERANT TO SALT 1 and

308 2) combined, and SPF1/2 (SUMO PROTEASE RELATED TO FERTILITY 1 and 2)

309 combined were tested (Fig. 1E, 1F, Supplementary Table S3). None of the

310 corresponding proteins appeared to be essential for survival at $28^{\circ} \mathrm{C}$. Likewise,

311 SUMO E4 ligase activity mediated by PIAL1/2 (PROTEIN INHIBITOR OF

312 ACTIVATED STAT LIKE 1 and 2) was not required for growth at $28^{\circ} \mathrm{C}$, alone or in

313 combination with SIZ1 (using the triple mutant siz1;pial1;pial2) (Supplementary Fig.

314 S1B). Also three complementation lines were examined that express a variant of the

315 E2 SUMO conjugating enzyme SCE1, SCE1(K15R), from its endogenous promoter

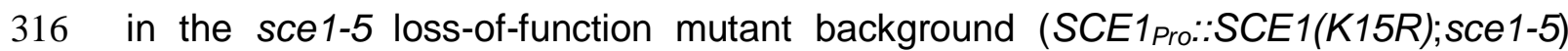

317 (Tomanov et al., 2018). These lines no longer form poly-SUMO chains, but SUMO is

318 still attached as monomer onto acceptor lysines. Loss of SUMO chain formation did

319 not result in thermo-lethality (Supplementary Fig. S1C). Thus, none of the other

320 mutants in the SUMO machinery displayed thermo-lethality. Except for the mutants

321 with dwarf rosettes (siz1-2, hpy1 and eds4), the SUMO machinery mutants tested

322 displayed all a normal thermomorphogenesis responses. This signifies that SUMO1/2

323 protein itself or mono-sumoylation of one or more substrates permits Arabidopsis to

324 survive $28^{\circ} \mathrm{C}$ independent of SIZ1.

325

326 Seven-day period at $28^{\circ} \mathrm{C}$ triggers thermo-lethality in sumo1/2 ${ }^{K D}$ and the $h s f A 1$

327 mutant eTK.

328 To assess if thermo-lethality is connected to protein damage, we determined whether

329 Arabidopsis mutants of known damage response regulators confer thermo-resilience

330 (Supplementary Table S3). Only one of these mutants showed thermo-lethality at 
$33128^{\circ} \mathrm{C}$, namely the mutant $e T K$ that lacks three of the HSFA1 isoforms ( $\left.h s f A 1 a, b, d\right)$

332 (Fig. 2). eTK was already known to collapse at $28^{\circ} \mathrm{C}$ (Liu and Charng, 2013). The

333 remaining family member, HSFA1e, can apparently not compensate for thermo-

334 sensitivity at $28^{\circ} \mathrm{C}$ and this isoform contributes also the least to thermotolerance (Liu 335 and Charng, 2013; Liu et al., 2011). In contrast, the mutant hsfA2 developed normally

336 at $28^{\circ} \mathrm{C}$ (Supplementary Fig. S1D, Supplementary Table S3). This is remarkable

337 as the HSFA2 gene is a major transcriptional target of HSFA1 in response to heat 338 stress (Liu and Charng, 2013).

339 We compared thermo-sensitivity of sumo $1 / 2^{K D}$ and $e T K$ by varying the length 340 of the warm period at different developmental stages. First, the mutants were 341 germinated at a normal $\left(22^{\circ} \mathrm{C}\right)$ or warm temperatures $\left(28^{\circ} \mathrm{C}\right)$ and then after 7,14 or

34221 days the plants were shifted to the opposite temperature and their survival was 343 scored at 28 days (Fig. 2A, 2C). As positive control for a 'temperature-sensitive 344 growth phenotype', the mutant bon1 was included as its autoimmune dwarf 345 phenotype fully recovers at $28^{\circ} \mathrm{C}$ (Yang and Hua, 2004). Indeed, the size of bon1 346 increased with more time at $28^{\circ} \mathrm{C}$ (Fig. 2B). Strikingly, an initial 'cool' period of one 347 week at $22^{\circ} \mathrm{C}$ was sufficient to prevent thermo-lethality of sumo $1 / 2^{K D}$ even when this 348 was followed by three weeks at $28^{\circ} \mathrm{C}$ although the rosette remained compact (Fig. 349 2B, 2B.1). When sumo $1 / 2^{K D}$ was first grown at $22^{\circ} \mathrm{C}$ for two weeks followed by a 350 warm period of two weeks, its rosette adopted a flat morphology while the rosette 351 size increased. This change in morphology suggested that auto-immunity was 352 partially suppressed by the warm temperature. These sumo $1 / 2^{K D}$ plants still failed to 353 show petiole and hypocotyl elongation in response to $28^{\circ} \mathrm{C}$, which confirms again 354 that the thermomorphogenesis response is compromised (Hammoudi et al., 2018). In 355 contrast to sumo $1 / 2^{K D}$, eTK seedlings already collapsed when they experienced only $35628^{\circ} \mathrm{C}$ during the final week of the experiment (week 4)(Supplementary Fig. S1E). 357 Apparently, thermo-lethality of $e T K$ is independent of its developmental stage, i.e. it 358 occurred upon germination and when the plants were three weeks-old.

359 In the reverse experiment, i.e. warm start followed by a cool period (Fig. 2C 360 and D), recovery of the bon1 dwarf phenotype was again more pronounced when the 361 warm period lasted longer. In contrast, sumo $1 / 2^{K D}$ collapsed as soon as the warm 362 period lasted two weeks or more. However, several sumo1/2 ${ }^{K D}$ plants survived when 363 the warm start was only one week (3/24 survivors). The eTK seedlings died already 
364 when they experienced one week at $28^{\circ} \mathrm{C}$. We then quantified the survival rate of the

365 seedlings in response to a warm start that lasted one to maximum eight days, before

366 returning them to a normal temperature regime of $22^{\circ} \mathrm{C}$ (Fig. 2E). The survival rate

367 was still $>75 \%$ when sumo $1 / 2^{K D}$ experienced a period of maximum five days at $28^{\circ} \mathrm{C}$.

368 After seven or eight days at $28^{\circ} \mathrm{C}$, the survival rate had dropped to $60 \%$ and $25 \%$,

369 respectively, suggesting that the median lethal dose $\left(L D_{50}\right)$ of a warm period was

370 approximately seven days for sumo1/2KD.

372 A warm pulse of seven days reflects a lethal dose for sumo1/2 ${ }^{K D}$ and $e T K$.

373 To evaluate whether growth of sumo $1 / 2^{K D}$ and $e T K$ resumes after a warm period, 374 seeds were germinated at a normal temperature $\left(22^{\circ} \mathrm{C}\right)$. After two weeks, the 375 seedings received a warm period $\left(28^{\circ} \mathrm{C}\right.$ ) of variable length (2 to 14 days) after which 376 they returned to $22^{\circ} \mathrm{C}$ for the remainder of the experiment (Fig. 3A-C). In parallel, 377 control plants were placed at a constant temperature $\left(22^{\circ} \mathrm{C}\right.$ or $\left.28^{\circ} \mathrm{C}\right)$, and one set 378 remained at $28^{\circ} \mathrm{C}$ upon the shift to this temperature $\left(22^{\circ} \mathrm{C} \rightarrow 28^{\circ} \mathrm{C}\right)$. As internal control 379 for the temperature treatments, bon1 and siz1 were included again (Fig. 3D). As 380 expected, bon1 and siz1 showed progressively more growth recovery with more time 381 spent at $28^{\circ} \mathrm{C}$ (Fig. 3D), confirming that the temperature treatments were effective.

382 This experiment revealed that development of the vegetative tissue of 383 sumo $1 / 2^{K D}$ was stalled as soon as the $28^{\circ} \mathrm{C}$-period lasted ten days or more, while 384 growth continued for sumo $1 / 2^{K D}$ when this period was only six days (Fig. 3B, 3C).

385 After the ten-day warm period, the sumo $1 / 2^{K D}$ rosette turned necrotic over the next 38620 days while it developed an irregular inflorescence. The warm period of only six 387 days triggered only growth retardation of sumo $1 / 2^{K D}$ in comparison to control at $22^{\circ} \mathrm{C}$. 388 For $e T K$, a similar observation was made, i.e. ten days at $28^{\circ} \mathrm{C}$ resulted in collapse, 389 while growth of $e T K$ resumed after a six-day warm period. Hence, it is not the 390 developmental stage of the mutants, but rather the length of the warm period that 391 defines thermo-lethality for both mutants.

392

393 The shoot apical meristem of sumo1/2 ${ }^{K D}$ becomes highly irregular at $28^{\circ} \mathrm{C}$

394 As sumo $1 / 2^{K D}$ and eTK failed to resume growth after a warm period, the integrity of 395 their shoot and root meristems was examined using microscopy (Fig. 4 and Fig. 5). 396 Strikingly, integrity of the shoot apical meristem (SAM) and tissue organization were 
397 lost when sumo $1 / 2^{K D}$ was incubated at $28^{\circ} \mathrm{C}$, i.e. the cell division patterning and cell 398 size were highly irregular at $28^{\circ} \mathrm{C}$, but not $22^{\circ} \mathrm{C}$ despite the early floral transition (Fig.

399 4A-C, 4E, red arrows). In contrast, the structure of the SAM and cell division 400 patterning were normal for the wildtype (Col-0) and siz1-2 plants irrespective of the 401 temperature regime given $\left(22^{\circ} \mathrm{C}\right.$ and $\left.28^{\circ} \mathrm{C}\right)$ (Fig. 4B, 4D). We also inspected the 402 SAM of $e T K$, but tissue dissection of the eTK shoot meristem was only possible till 403 four days at $28^{\circ} \mathrm{C}$. Similar to sumo $1 / 2^{K D}$, eTK had an irregular meristem at $28^{\circ} \mathrm{C}$, but 404 not at $22^{\circ} \mathrm{C}$ (Fig. 4D). Patterning of the SAM of sumo1/2 ${ }^{K D}$ was not restored within 7 405 days upon the return to $22^{\circ} \mathrm{C}$. Thus, the SAM is overly sensitive to increased ambient 406 temperatures, and HSFA1 as well as SUMO (conjugation) are critical for this thermo407 resilience.

408 We also measured whether growth of the main and lateral roots was halted in 409 response to $28^{\circ} \mathrm{C}$. Although the main root length of sumo $1 / 2^{K D}$ appeared to be 410 shorter at $28^{\circ} \mathrm{C}$, this was not significantly different from the growth reduction seen for 411 the wild type control (Col-0) (Fig. 5A). This was the case for seedlings that were 412 directly placed at $28^{\circ} \mathrm{C}$ as well as for plants that experienced first $22^{\circ} \mathrm{C}$ and then $41328^{\circ} \mathrm{C}$. This experiment thus reveals that, in contrast to the SAM, growth of the 414 primary root of sumo $1 / 2^{K D}$ was not arrested at $28^{\circ} \mathrm{C}$. Moreover, sumo $1 / 2^{K D}$ developed 415 less lateral roots than the wild type Col-0, but this was independent of the ambient 416 temperature $\left(22^{\circ} \mathrm{C}\right.$ vs. $\left.28^{\circ} \mathrm{C}\right)$ (Fig. 5B). In contrast, growth of the primary root of $e T K$ 417 was strongly inhibited at $28^{\circ} \mathrm{C}$ but not at $22^{\circ} \mathrm{C}$. Furthermore, lateral root formation 418 was absent for $e T K$ at $28^{\circ} \mathrm{C}$ while normal at $22^{\circ} \mathrm{C}$. These data reveal again that 419 SUMO and HSFA1 prevent thermo-lethality, but they likely do so via different 420 mechanisms.

421 We also inspected development of the root apical meristem in response to 422 high ambient temperatures using confocal microscopy (Fig. 5C). Although sumo1/2 ${ }^{K D}$ 423 displayed irregular divisions together with dead cells in the cortex and endodermis 424 (i.e. propidium iodide-positive cells), the overall architecture of the root tip appeared 425 to be intact at $22^{\circ} \mathrm{C}$ and $28^{\circ} \mathrm{C}$. This is highly reminiscent of the SUMO E3 ligase 426 mutant mms21/hpy2 that also shows irregular divisions together with dead cells (Xu 427 et al., 2013). In contrast, the lateral root primordia of sumo1/2KD were highly irregular 428 at $28^{\circ} \mathrm{C}$, but not at $22^{\circ} \mathrm{C}$. This deformation of the lateral root primordia of sumo $1 / 2^{K D}$ 429 at $28^{\circ} \mathrm{C}$ resembles the reported lateral root phenotype of the PLETHORA mutant 
430 plt357 (Du and Scheres, 2017; Hofhuis et al., 2013), indicative for a defect in lateral

431 root meristem organization.

432

433 In contrast to eTK, sumo1/2 ${ }^{K D}$ seedlings withstand heat, abiotic and proteotoxic 434 stress

435 HSFA1 is required for acquired thermotolerance, i.e. eTK is highly sensitive to heat 436 stress at $44^{\circ} \mathrm{C}$ even after pre-exposure to $37^{\circ} \mathrm{C}$ followed by an acclimation period (Liu 437 et al., 2011). In contrast, SIZ1 is important for ( $i$ ) basal thermotolerance $\left(39^{\circ} \mathrm{C}\right.$ for up 438 to 4 hours) and (ii) the sharp rise in SUMO adduct levels in response to acute heat 439 stress $\left(30 \mathrm{~min}\right.$ at $\left.37^{\circ} \mathrm{C}\right)\left(\mathrm{Yoo}\right.$ et al., 2006). As sumo1/2 ${ }^{K D}$ mimics to some extent the 440 phenotype of $e T K$, we tested whether acquired thermotolerance is compromised in 441 sumo $1 / 2^{K D}$ (Fig. 6A). Whereas eTK collapsed after a $44^{\circ} \mathrm{C}$ treatment irrespective of a 442 length of the acclimation period (SAT/LAT), sumo1/2 ${ }^{K D}$ and siz1 both survived this 443 noxious temperature of $44^{\circ} \mathrm{C}$ after an acclimation period. This denotes once more 444 that thermo-lethality of sumo $1 / 2^{K D}$ at $28^{\circ} \mathrm{C}$ is not caused by a loss of HSFA1 activity 445 or a failure to regulate the heat-induced transcriptional response (like HSFA2 446 upregulation) that promotes heat acclimation. Next, we assessed whether sumo $1 / 2^{K D}$ 447 could cope with proteotoxic stress (due to incorporation of L-canavanine for arginine 448 in proteins), water stress (high mannitol) and salt stress, as siz1 and eTK are 449 sensitive to different extents to these conditions (Castro et al., 2015; Liu and Charng, 450 2013). SUMO adduct levels are also known to increase in response to proteotoxic 451 and abiotic stresses (Conti et al., 2008; Kurepa et al., 2003; Miller et al., 2013). In 452 fact, the notion is that sumoylation is pivotal for the recovery response to nuclear 453 protein damage (at least) in mammals (Liebelt et al., 2019; Seifert et al., 2015). 454 Whereas eTK grew poorly on $10 \mu \mathrm{M}$ L-Canavanine, $300 \mathrm{mM}$ mannitol or $0.75 \mathrm{mM}$ $455 \mathrm{NaCl}$, both sumo1/2 ${ }^{K D}$ and siz1 seedlings grew relatively normally (Supplementary 456 Fig. S2). We included in this case also siz1;pad4 and sumo1/2 ${ }^{K D} ;$ pad4, to determine 457 whether the sensitivity would be due to high SA levels, but this did not change the 458 outcome. This experiment thus support the idea that the meristem collapse of sumo $1 / 2^{K D}$ at $28^{\circ} \mathrm{C}$ is not a result of compromised HSFA1 activity.

460 
463 We also examined the protein levels of known markers of the cellular protein damage 464 response (HSP70, HSP90 and HSP101, and SUMO1/2). To this end, their levels 465 were examined after heat stress $\left(37^{\circ} \mathrm{C}, 30 \mathrm{~min}\right)$. Whereas HSP101 is critical for acquired thermotolerance (Hong and Vierling, 2001), the other proteins have a broad role in the protein damage response. As expected, heat stress triggered a global increase in SUMO conjugate levels in wild type plants, which was largely absent in sumo $1 / 2^{K D}$ while strongly reduced in siz1 and eTK (Fig. 6B). The latter suggests that (i) the HSFA1 protein levels, (ii) HSFA1 signaling and/or (iii) HSFA1 shuttling to the nucleus is important for the rise in SUMO1/2 conjugate levels in response to heat stress.

The HSP90 and HSP101 levels did not differ between sumo1/2 ${ }^{K D}$, siz1 and the wild type control (Col-0) after a heat shock. These similar protein profiles indicate again that HSFA1-dependent heat stress response is intact in the SUMO conjugation mutants. In contrast, HSP101 largely fails to accumulate in eTK after a heat shock, which matches with the loss of acquired thermotolerance in eTK. The levels of HSP90 and HSP101 were also examined in response to a sustained warm period at $28^{\circ} \mathrm{C}$ (4 hours and 7 days). A warm period had hardly any effect on the HSP9O and HSP101 protein levels in sumo1/2 ${ }^{K D}$, siz1 and the wild type control (Fig. 6C). In contrast, HSP101 levels were again low in eTK, while HSP90 levels were slightly reduced. HSFA2 levels displayed a modest transient increase in all lines except for eTK after 4 hours at $28^{\circ} \mathrm{C}$. This substantiates the other findings that HSFA1 signaling is largely intact sumo1/2KD and siz1. As the wildtype (Col-0) and eTK plants did not show a change in their free and conjugated SUMO levels in response to $28^{\circ} \mathrm{C}$, we also conclude that a warm period does not lead to a global (persistent) imbalance in SUMO (conjugate) levels.

The transcriptional response differs between sumo1/2 ${ }^{K D}$ and $e T K$ in response to $28^{\circ} \mathrm{C}$.

491 Besides that sumo1/2 $2^{K D}$ and $\operatorname{siz} 1$ show a delayed and reduced transcriptional response to $28^{\circ} \mathrm{C}$ linked to a compromised thermomorphogenesis response

493 (Hammoudi et al., 2018), we assessed whether the transcriptional response of 494 sumo $1 / 2^{K D}$ to a warm period is mirrored in part by the response of eTK. To avoid side 495 effects in the gene expression profiles due to autoimmunity in the two sumoylation- 
496 deficient mutants, the pad4-1 mutation was used again as genetic background. We

497 determined the differentially expressed genes (DEGs) between the lines at each time

498 point in response to the temperature shift (Fig 7A, Supplementary Dataset S1). As

499 already reported (Hammoudi et al., 2018), sumo1/2KD;pad4; and siz1;pad4 show a

500 strong overlap in their gene expression profiles 24 and $96 \mathrm{hrs}$ after the temperature

501 shift to $28^{\circ} \mathrm{C}$, while the DEGs for eTK show less overlap with sumo1/2KD;pad4 (Fig

502 7A). A principal component analysis (PCA), both on the DEGs and the normalized

503 expression data (i.e. without preselection of DEGs) revealed that eTK clusters

504 separate from the other three genotypes in this PCA, both at 22 and $28^{\circ} \mathrm{C}$ (Fig 7B

505 and Supplementary Fig. S3A). After $24 \mathrm{~h}$ at $28^{\circ} \mathrm{C}$, three clusters are visible in the

506 PCA, i.e. (1) pad4, (2) eTK, and (3) sumo1/2 ${ }^{K D}$;pad4 and siz1;pad4 combined. At this

507 stage, the first principal component axis, PC1, distinguishes both eTK and pad4 from

508 the sumoylation-deficient mutants. A gene ontology (GO) analysis was then used to

509 identify biological processes that are significantly overrepresented amongst the top

510500 DEGs that define the PC axes (Fig 7C, Supplementary Fig. S3B,

511 Supplementary Dataset S2-S4). For PC1 we find an overrepresentation of the GO

512 terms 'cell division', 'DNA replication', 'chromosome organization', ‘(mitotic) cell

513 cycle', 'microtubule movement' and 'DNA metabolic process' of the PCA. These GO

514 terms were also overrepresented at the late time point $\left(96 \mathrm{~h}\right.$ at $\left.28^{\circ} \mathrm{C}\right)$, but they now

515 contribute to PC2, which separates siz1;pad4 from pad4-1 while sumo1/2 ${ }^{K D}$;pad4

516 takes an intermediate position. These GO terms were not significantly

517 overrepresented for PC1 and PC2 prior to the temperature shift $\left(22^{\circ} \mathrm{C}\right)$. This

518 suggests that the loss of SIZ1-dependent sumoylation alters the transcriptional

519 response linked to plant growth when the temperature increases. This is in line with

520 the fact that the thermomorphogenesis response is compromised in siz1-2. When

521 looking at the other axis (PC1 at T1-24h and PC2 at T2-96h), we see that the GO

522 terms 'response to stress', 'response to abiotic stimulus' 'defense response', 'innate

523 immune response', 'response to temperature are overrepresented. These results did

524 not change when we performed an unbiased PCA on the top 500 genes that

525 contribute to the PC loadings based on the entire gene chip dataset (Supplementary

526 Fig. S3B and Supplementary Dataset S4). The majority of the DEGs was detected

527 for $e T K$ after $96 \mathrm{~h}$ at $28^{\circ} \mathrm{C}$ when this mutant already collapses (visualized by PC1 at

528 this stage that explains $73 / 78 \%$ ). Importantly, none of the GO terms identified for 
$529 \mathrm{PC} 1$ at $\mathrm{T}=1$ or $\mathrm{PC} 2$ for $\mathrm{T}=4$ ( $24 \mathrm{~h}$ and 96 after the shift $28^{\circ} \mathrm{C}$, respectively) was

530 already significant prior to shift $28^{\circ} \mathrm{C}$. Evidently, the transcriptional responses of

531 sumo $1 / 2^{K D}$ and $e T K$ differ despite the fact that both are hypersensitive for a

532 prolonged period at $28^{\circ} \mathrm{C}$.

533

\section{DISCUSSION}

535 Here we report that SUMO1 and -2 combined are essential for Arabidopsis to endure 536 sustained warm periods of $28^{\circ} \mathrm{C}$ (as depicted in a model in Supplementary Fig S4).

537 None of the other components of the SUMO (de)conjugation machinery tested 538 appeared to be required for thermo-resilience-alone or in combination. We also 539 found that poly-SUMO chain formation is not necessary to sustain warm 540 temperatures. This implies that SUMO thermo-resilience apparently depends on mono-sumoylation of one or more substrates. At the tissue level, we found that in particular the integrity of the shoot apical meristem and lateral root primordia was lost

543 in the SUMO1/2 (conjugation) knockdown mutant when plants were grown at $28^{\circ} \mathrm{C}$.

544 This deformation of the lateral root primordia of sumo $1 / 2^{K D}$ resembled the lateral root 545 phenotype of the PLETHORA mutant plt357 (Du and Scheres, 2017; Hofhuis et al., 546 2013). These PLETHORA transcription factors are required for the formative 547 periclinal cell divisions that initiate lateral root primordia. Apparently, SUMO has a 548 role in lateral root initiation. In the sumo1/2 ${ }^{K D}$, this process is foremost disturbed at increased temperatures, possibly via a pathway that involves PLT3/PLT5/PLT7, which together also control Arabidopsis phyllotaxis (Hofhuis et al., 2013). The role of SUMO1/2 for meristem integrity at elevated temperatures was independent of

552 EDS1/PAD4 and accumulation of the defense hormone salicylic acid by SID2. Thus, 553 thermo-resilience is a third aspect of the pleiotropic phenotype of the sumo1/2 ${ }^{K D}$ 554 mutant-besides inhibition of SNC1-dependent autoimmunity and 555 thermomorphogenesis (Hammoudi et al., 2018; van den Burg et al., 2010).

556 Our finding that SUMO confers thermo-resilience to warm periods was 557 previously reported for HSFA1 (Liu et al., 2011). In general, HSFA1 is regarded to be 558 the master regulator of the heat-stress response. Nonetheless, we see differences 559 between sumo $1 / 2^{K D}$ and $e T K$, suggesting that the two proteins act in different 560 (regulatory) processes. First, SUMO was not required for both short- and long-term 561 acquire thermotolerance while HSFA1 is. Second, accumulation of the chaperones 
562 HSP90 and HSP101 but also the transcription factor HSFA2 was largely intact in

$563 s u m o 1 / 2^{K D}$ and siz1 in response to heat stress or increased ambient temperatures,

564 but not in eTK. Both HSP101 and HSFA2 protein levels are well known markers for

565 heat-stress induced nuclear activity of HSFA1 (Busch et al., 2005; Liu et al., 2011).

566 This experiment thus suggests that HSFA1 is still responsive when heat stress

567 (protein damage) is applied to sumo $1 / 2^{K D}$ and siz1. The transcriptional profile of

568 sumo $1 / 2^{K D}$;pad4 resembles also more that of siz1;pad4 than eTK in response to

569 warm conditions. We also noted that $e T K$ does not germinate at $28^{\circ} \mathrm{C}$, while

570 sumo $1 / 2^{K D}$ does germinate but it collapse within 2 weeks post germination.

571 Combined these findings argue that the HSFA1 regulatory pathway is largely intact

572 and responsive in the sumoylation-deficient mutants sumo1/2 ${ }^{K D}$ and siz1.

573 Mammals express two close homologues of Arabidopsis HSFA1, called HSF1

574 and HSF2. HSF1 and -2 undergo stress-induced sumoylation, which modulates their

575 transcriptional activity and DNA affinity (Akerfelt et al., 2010; Anckar et al., 2006;

576 Goodson et al., 2001; Hietakangas et al., 2003; Hong and Vierling, 2001). Also in

577 plants, different HSF family members (HSFA1b, HSFA1d, HSFA2 and HSFB2b) and

578 some downstream targets (e.g. DREB2A) are subject to sumoylation (Augustine and

579 Vierstra, 2018; Cohen-Peer et al., 2010; Miller et al., 2010; Rytz et al., 2018; Wang et

580 al., 2020). Of note, none of these HSF transcription factors appeared to be

581 sumoylated in a SIZ1-dependent manner (Rytz et al., 2018). The latter would favor

582 that SCE1 directly targets these HSFs for SUMOylation. Yet the biological

583 consequence of HSFA1 sumoylation remains unknown. In the case of tomato

584 HSFA2, sumoylation was suggested to negatively control its transcriptional activity

585 (Cohen-Peer et al., 2010). As the Arabidopsis hsfa2 mutant showed normal thermo-

586 resilience to $28^{\circ} \mathrm{C}$, it is unlikely that HSFA2 is important for the here seen SUMO-

587 mediated thermo-resilience. Also many chaperones including HSP9O are SUMO

588 modified in mammals and yeast (Panse et al., 2004; Pountney et al., 2008; Zhou et

589 al., 2004). In Arabidopsis HSP90 was shown to inhibit HSFA1 by sequestrating the

590 protein outside of the nucleus (Yoshida et al., 2011; Zou et al., 1998). Hence, HSP90

591 directly acts on HSFA1 in a negative feedback loop, although in absence of HSP90,

592 other factors may be required to strongly activate HSFA1 in the nucleus during stress

593 conditions (Yoshida et al., 2011). We observed that the rapid increase in SUMO

594 conjugates due to acute heat stress in part also depends on HSFA1. Possibly, 
595 HSFA1 sequesters SUMO and/or the E2 enzyme under normal conditions.

596 Alternatively, activation and nuclear translocation of HSFA1 might impact the SUMO

597 conjugate levels by promoting SUMO conjugation and/or by reducing SUMO

598 protease activity. Clearly, future studies should determine how the HSFA1/HSP90

599 regulatory network affects SUMO and how SUMO affects the plant proteostasis in

600 response to acute heat stress, but also a mild increase of the ambient temperature.

601 At this stage we cannot rule out that SUMO conjugation modulates HSFA1 activity

602 directly or part of its downstream responses. Clear follow up questions are: does

603 SUMO modification of HSFA1 impact the interaction with HSP90 in the cytosol or the 604 nuclear functions of HSFA1 when bound to HRE cis-regulatory elements? And why is

605 the meristem sensitive to loss of HSFA1 and SUMO?

606

\section{Supplementary data}

608 Supplementary data are available at JXB online.

609

610 Table S1. Resources used in this study

611 Table S2. Primers used in this study

612 Table S3. Details for Arabidopsis plant genotyping

613 Fig. S1. Growth phenotype of different heat-sensitive mutants at $22^{\circ} \mathrm{C}$ and $28^{\circ} \mathrm{C}$.

614 Fig. S2. Response of sumo1/2 ${ }^{K D}$ to different abiotic and proteotoxic stresses.

615 Fig. S3. Unbiased gene ontology enrichment analysis of the gene expression data in

616 response to warm ambient temperatures for sumo1/2 ${ }^{K D}$;pad4-1, siz1-2;pad4 and

617 triple HSFA1 mutant eTK in comparison to pad4-1.

618 Fig. S4. Diagram depicting the role of SUMO and HSFA1 in thermo-resilience and

619 heat stress.

620 Dataset S1. Datasheet with the DEGs detected in sumo1/2KD pad4, siz1 pad4, and

$621 e T K$ in comparison to the control plant (pad4-1) at the different time points $\left(22^{\circ} \mathrm{C}\right.$,

$62228^{\circ} \mathrm{C}-24 \mathrm{~h}$ and $\left.28^{\circ} \mathrm{C}-96 \mathrm{~h}\right)$.

623 Dataset S2. Datasheet with the top500 DEGs that contributed to loading of PC1 and

624 PC2 at each time points $\left(22^{\circ} \mathrm{C}, 28^{\circ} \mathrm{C}-24 \mathrm{~h}\right.$ and $\left.28^{\circ} \mathrm{C}-96 \mathrm{~h}\right)$; Gene ID list was used to 625 perform the GO term analysis shown in Fig 7C. 
626 Dataset S3. Datasheet with the top500 genes that contributed to loading of PC1 and

627 PC2 at each time points $\left(22^{\circ} \mathrm{C}, 28^{\circ} \mathrm{C}-24 \mathrm{~h}\right.$ and $\left.28^{\circ} \mathrm{C}-96 \mathrm{~h}\right)$; Gene ID list was used to

628 perform the GO term analysis shown in Fig S4B.

629 Dataset S4. Datasheet with the selected Gene ontology terms for the (a) top500

630 genes for the DEGs (Fig 7C) and the top500 genes unbiased that contributed to the

631 loading of the PC axis (Fig S4B)

632

633 Acknowledgments

634 We thank Like Fokkens, Jeffrey Ham, Ludek Tikovsky, Harold Lemereis for help with 635 gene expression analyses, genotyping, and plant maintenance, respectively. We

636 express our gratitude to all colleagues who supplied seeds and materials. This work

637 was supported by grants of Netherlands Scientific Organisation (ALW-VIDI

638 864.10.004 to HvdB; TTW14948 to TH). We thank the Van Leeuwenhoek Centre for

639 Advanced Microscopy (SILS-University of Amsterdam) for use of microscopy

640 facilities.

641

\section{Author contributions}

$643 \mathrm{HB}$ and $\mathrm{VH}$ designed the research with input from all authors.

$644 \mathrm{VH}, \mathrm{BB}$, and HB performed and analyzed plant growth experiments.

$645 \mathrm{MK}, \mathrm{BB}$ and HB performed and analyzed the root growth experiments.

$646 \mathrm{HB}, \mathrm{MG}, \mathrm{TH}$ and BB performed the SEM experiments.

647 BB performed the immunoblot analysis and abiotics stress plate assay

648 MJ and HB performed the gene expression analysis. BB prepared the RNA samples.

649 BB prepared and analyzed the protein data.

650 HB wrote the final manuscript with input from all authors

651

\section{Data availability}

653 All data supporting the findings of this study are available within the paper and its

654 supplementary materials published on line. The original microarray data that support

655 the findings of this study are openly available in the GEO database at NCBI

656 (https://www.ncbi.nlm.nih.gov/geo) under accession number GSE97641. 


\section{References}

\section{Akerfelt M, Vihervaara A, Laiho A, Conter A, Christians ES, Sistonen L,} Henriksson E. 2010. Heat shock transcription factor 1 localizes to sex chromatin during meiotic repression. Journal of Biological Chemistry 285, 34469-34476. Anckar J, Hietakangas V, Denessiouk K, Thiele DJ, Johnson MS, Sistonen L. 2006. Inhibition of DNA binding by differential sumoylation of heat shock factors. Molecular and Cellular Biology 26, 955-964.

Augustine RC, Vierstra RD. 2018. SUMOylation: re-wiring the plant nucleus during stress and development. Current Opinion in Plant Biology 45, 143-154.

Busch W, Wunderlich M, SchöffI F. 2005. Identification of novel heat shock factordependent genes and biochemical pathways in Arabidopsis thaliana. Plant Journal 41, 1-14.

Casal JJ, Balasubramanian S. 2019. Thermomorphogenesis. Annual Review of Plant Biology 70, 321-346.

Castro PH, Verde N, Lourenço T, Magalhães AP, Tavares RM, Bejarano ER, Azevedo H. 2015. SIZ1-Dependent Post-Translational Modification by SUMO Modulates Sugar Signaling and Metabolism in Arabidopsis thaliana. Plant and Cell Physiology 56, 2297-2311.

Cohen-Peer R, Schuster S, Meiri D, Breiman A, Avni A. 2010. Sumoylation of Arabidopsis heat shock factor A2 (HsfA2) modifies its activity during acquired thermotholerance. Plant Molecular Biology 74, 33-45.

Conti L, Price G, O'Donnell E, Schwessinger B, Dominy P, Sadanandom A. 2008. Small ubiquitin-like modifier proteases OVERLY TOLERANT TO SALT1 and -2 regulate salt stress responses in Arabidopsis. Plant Cell 20, 2894-2908.

Czechowski T, Stitt M, Altmann T, Udvardi MK, Scheible WR. 2005. Genomewide identification and testing of superior reference genes for transcript normalization in Arabidopsis. Plant Physiology 139, 5-17.

Dickinson PJ, Kumar M, Martinho C, Yoo SJ, Lan H, Artavanis G, Charoensawan V, Schottler MA, Bock R, Jaeger KE, Wigge PA. 2018.

Chloroplast Signaling Gates Thermotolerance in Arabidopsis. Cell Reports 22, 16571665.

Ding Y, Shi Y, Yang S. 2020. Molecular Regulation of Plant Responses to Environmental Temperatures. Molecular Plant 13, 544-564. 
Du Y, Scheres B. 2017. PLETHORA transcription factors orchestrate de novo organ patterning during Arabidopsis lateral root outgrowth. Proceedings of the National Academy of Sciences USA 114, 11709-11714.

Golebiowski F, Matic I, Tatham MH, Cole C, Yin Y, Nakamura A, Cox J, Barton GJ, Mann M, Hay RT. 2009. System-wide changes to SUMO modifications in response to heat shock. Science Signaling 2, ra24.

Goodson ML, Hong Y, Rogers R, Matunis MJ, Park-Sarge OK, Sarge KD. 2001. Sumo-1 modification regulates the DNA binding activity of heat shock transcription factor 2, a promyelocytic leukemia nuclear body associated transcription factor. Journal of Biological Chemistry 276, 18513-18518.

Gou M, Huang Q, Qian W, Zhang Z, Jia Z, Hua J. 2017. Sumoylation E3 Ligase SIZ1 Modulates Plant Immunity Partly through the Immune Receptor Gene SNC1 in Arabidopsis. Molecular Plant-Microbe Interactions 30, 334-342.

Hammoudi V, Fokkens L, Beerens B, Vlachakis G, Chatterjee S, Arroyo-Mateos M, Wackers PFK, Jonker MJ, van den Burg HA. 2018. The Arabidopsis SUMO E3 ligase SIZ1 mediates the temperature dependent trade-off between plant immunity and growth. PLOS Genetics 14, e1007157.

Hammoudi V, Vlachakis G, de Jonge R, Breit TM, van den Burg HA. 2017. Genetic characterization of T-DNA insertions in the genome of the Arabidopsis thaliana sumo1/2 knock-down line. Plant Signaling \& Behaviour 12, e1293216.

Hietakangas V, Ahlskog JK, Jakobsson AM, Hellesuo M, Sahlberg NM, Holmberg Cl, Mikhailov A, Palvimo JJ, Pirkkala L, Sistonen L. 2003.

Phosphorylation of serine 303 is a prerequisite for the stress-inducible SUMO modification of heat shock factor 1. Molecular and Cellular Biology 23, 2953-2968.

Hightower LE. 1991. Heat shock, stress proteins, chaperones, and proteotoxicity. Cell 66, 191-197.

Hilgarth RS, Hong Y, Park-Sarge OK, Sarge KD. 2003. Insights into the regulation of heat shock transcription factor 1 SUMO-1 modification. Biochemical and Biophysical Research Communications 303, 196-200.

Hofhuis H, Laskowski M, Du Y, Prasad K, Grigg S, Pinon V, Scheres B. 2013. Phyllotaxis and rhizotaxis in Arabidopsis are modified by three PLETHORA transcription factors. Current Biology 23, 956-962. 
Hong SW, Vierling E. 2001. Hsp101 is necessary for heat tolerance but dispensable for development and germination in the absence of stress. Plant Journal 27, 25-35.

Hong YL, Rogers R, Matunis MJ, Mayhew CN, Goodson M, Park-Sarge OK, Sarge KD. 2001. Regulation of heat shock transcription factor 1 by stress-induced SUMO-1 modification. Journal of Biological Chemistry 276, 40263-40267.

Irizarry RA, Hobbs B, Collin F, Beazer-Barclay YD, Antonellis KJ, Scherf U, Speed TP. 2003. Exploration, normalization, and summaries of high density oligonucleotide array probe level data. Biostatistics 4, 249-264.

Kotak S, Larkindale J, Lee U, von Koskull-Döring P, Vierling E, Scharf KD. 2007. Complexity of the heat stress response in plants. Current Opinion in Plant Biology 10, 310-316.

Kumar SV, Wigge PA. 2010. H2A.Z-Containing Nucleosomes Mediate the Thermosensory Response in Arabidopsis. Cell 140, 136-147.

Kurepa J, Walker JM, Smalle J, Gosink MM, Davis SJ, Durham TL, Sung DY, Vierstra RD. 2003. The small ubiquitin-like modifier (SUMO) protein modification system in Arabidopsis. Journal of Biological Chemistry 278, 6862-6872.

Lee J, Nam J, Park HC, Na G, Miura K, Jin JB, Yoo CY, Baek D, Kim DH, Jeong JC, Kim D, Lee SY, Salt DE, Mengiste T, Gong Q, Ma S, Bohnert HJ, Kwak SS, Bressan RA, Hasegawa PM, Yun DJ. 2007. Salicylic acid-mediated innate immunity in Arabidopsis is regulated by SIZ1 SUMO E3 ligase. Plant Journal 49, 79-90.

Liebelt F, Sebastian RM, Moore CL, Mulder MPC, Ovaa H, Shoulders MD, Vertegaal ACO. 2019. SUMOylation and the HSF1-Regulated Chaperone Network Converge to Promote Proteostasis in Response to Heat Shock. Cell Reports 26, 236249 e234.

Liu HC, Charng YY. 2013. Common and distinct functions of Arabidopsis class A1 and A2 heat shock factors in diverse abiotic stress responses and development. Plant Physiology 163, 276-290.

Liu HC, Liao HT, Charng YY. 2011. The role of class A1 heat shock factors (HSFA1s) in response to heat and other stresses in Arabidopsis. Plant, Cell and Environment 34, 738-751.

Miller MJ, Barrett-Wilt GA, Hua Z, Vierstra RD. 2010. Proteomic analyses identify a diverse array of nuclear processes affected by small ubiquitin-like modifier 
conjugation in Arabidopsis. Proceedings of the National Academy of Sciences USA 107, $16512-16517$.

Miller MJ, Scalf M, Rytz TC, Hubler SL, Smith LM, Vierstra RD. 2013. Quantitative proteomics reveals factors regulating RNA biology as dynamic targets of stressinduced SUMOylation in Arabidopsis. Molecular and Cellular Proteomics 12, 449463.

Miller MJ, Vierstra RD. 2011. Mass spectrometric identification of SUMO substrates provides insights into heat stress-induced SUMOylation in plants. Plant Signaling \& Behavior 6, 130-133.

Nishizawa-Yokoi A, Nosaka R, Hayashi H, Tainaka H, Maruta T, Tamoi M, Ikeda M, Ohme-Takagi M, Yoshimura K, Yabuta Y, Shigeoka S. 2011. HsfA1d and HsfA1e involved in the transcriptional regulation of HsfA2 function as key regulators for the Hsf signaling network in response to environmental stress. Plant and Cell Physiology 52, 933-945.

Ohama N, Kusakabe K, Mizoi J, Zhao H, Kidokoro S, Koizumi S, Takahashi F, Ishida T, Yanagisawa S, Shinozaki K, Yamaguchi-Shinozaki K. 2016. The transcriptional cascade in the heat stress response of Arabidopsis is strictly regulated at the level of transcription factor expression. Plant Cell 28, 181-201.

Olate E, Jimenez-Gomez JM, Holuigue L, Salinas J. 2018. NPR1 mediates a novel regulatory pathway in cold acclimation by interacting with HSFA1 factors. Nature Plants 4, 811-823.

Panse VG, Hardeland U, Werner T, Kuster B, Hurt E. 2004. A proteome-wide approach identifies sumoylated substrate proteins in yeast. Journal of Biological Chemistry 279, 41346-41351.

Pinto MP, Carvalho AF, Grou CP, Rodríguez-Borges JE, Sá-Miranda C, Azevedo JE. 2012. Heat shock induces a massive but differential inactivation of SUMOspecific proteases. Biochimica et Biophysica Acta 1823, 1958-1966.

Pountney DL, Raftery MJ, Chegini F, Blumbergs PC, Gai WP. 2008. NSF, Unc18-1, dynamin-1 and HSP90 are inclusion body components in neuronal intranuclear inclusion disease identified by anti-SUMO-1-immunocapture. Acta Neuropathologica 116, 603-614. 
Qiu Y, Li M, Kim RJ, Moore CM, Chen M. 2019. Daytime temperature is sensed by phytochrome $B$ in Arabidopsis through a transcriptional activator HEMERA. Nature Communications 10, 140.

Queitsch C, Hong SW, Vierling E, Lindquist S. 2000. Heat shock protein 101 plays a crucial role in thermotolerance in Arabidopsis. Plant Cell 12, 479-492.

Quint M, Delker C, Franklin KA, Wigge PA, Halliday KJ, van Zanten M. 2016. Molecular and genetic control of plant thermomorphogenesis. Nature Plants 2 , 15190.

Rytz TC, Miller MJ, McLoughlin F, Augustine RC, Marshall RS, Juan YT, Charng YY, Scalf M, Smith LM, Vierstra RD. 2018. SUMOylome profiling reveals a diverse array of nuclear targets modified by the SUMO ligase SIZ1 during heat stress. Plant Cell 30, 1077-1099.

Seifert A, Schofield P, Barton GJ, Hay RT. 2015. Proteotoxic stress reprograms the chromatin landscape of SUMO modification. Science Signaling 8, rs7.

Smyth GK. 2004. Linear models and empirical bayes methods for assessing differential expression in microarray experiments. Statistical Applications in Genetics and Molecular Biology 3, Article3.

Storey JD, Tibshirani R. 2003. Statistical significance for genomewide studies.

Proceedings of the National Academy of Sciences USA 100, 9440-9445.

Tatham MH, Matic I, Mann M, Hay RT. 2011. Comparative proteomic analysis identifies a role for SUMO in protein quality control. Science Signaling 4, rs4.

Tian T, Liu Y, Yan H, You Q, Yi X, Du Z, Xu W, Su Z. 2017. agriGO v2.0: a GO analysis toolkit for the agricultural community, 2017 update. Nucleic Acids Res 45, W122-W129.

Tomanov K, Nehlin L, Ziba I, Bachmair A. 2018. SUMO chain formation relies on the amino-terminal region of SUMO-conjugating enzyme and has dedicated substrates in plants. Biochemical Journal 475, 61-74.

van den Burg HA, Kini RK, Schuurink RC, Takken FLW. 2010. Arabidopsis Small ubiquitin-like modifier paralogs have distinct functions in development and defense. Plant Cell 22, 1998-2016.

Wang F, Liu Y, Shi Y, Han D, Wu Y, Ye W, Yang H, Li G, Cui F, Wan S, Lai J, Yang C. 2020. SUMOylation stabilizes the transcription factor DREB2A to improve plant thermotolerance. Plant Physiology 183, 41-50. 
Wang W, Vinocur B, Shoseyov O, Altman A. 2004. Role of plant heat-shock proteins and molecular chaperones in the abiotic stress response. Trends in Plant Sciences 9, 244-252.

Wu C. 1995. Heat shock transcription factors: structure and regulation. Annual Review of Cell and Developmental Biology 11, 441-469.

Xu P, Yuan D, Liu M, Li C, Liu Y, Zhang S, Yao N, Yang C. 2013. AtMMS21, an SMC5/6 complex subunit, is involved in stem cell niche maintenance and DNA damage responses in Arabidopsis roots. Plant Physiology 161, 1755-1768.

Yang S, Hua J. 2004. A haplotype-specific Resistance gene regulated by BONZAI1 mediates temperature-dependent growth control in Arabidopsis. Plant Cell 16, 10601071.

Yoo CY, Miura K, Jin JB, Lee J, Park HC, Salt DE, Yun DJ, Bressan RA, Hasegawa PM. 2006. SIZ1 small ubiquitin-like modifier E3 ligase facilitates basal thermotolerance in Arabidopsis independent of salicylic acid. Plant Physiology 142, 1548-1558.

Yoshida T, Ohama N, Nakajima J, Kidokoro S, Mizoi J, Nakashima K, Maruyama K, Kim JM, Seki M, Todaka D, Osakabe Y, Sakuma Y, Schoffl F, Shinozaki K, Yamaguchi-Shinozaki K. 2011. Arabidopsis HsfA1 transcription factors function as the main positive regulators in heat shock-responsive gene expression. Molecular Genetics and Genomics 286, 321-332.

Yu GC, Wang LG, Han YY, He QY. 2012. clusterProfiler: an R Package for comparing biological themes among gene clusters. Omics-a Journal of Integrative Biology 16, 284-287.

Zhou W, Ryan JJ, Zhou H. 2004. Global analyses of sumoylated proteins in Saccharomyces cerevisiae. Induction of protein sumoylation by cellular stresses. Journal of Biological Chemistry 279, 32262-32268.

Zhu Y, Qian W, Hua J. 2010. Temperature modulates plant defense responses through NB-LRR proteins. PLOS Pathogens 6, e1000844.

Zou J, Guo Y, Guettouche T, Smith DF, Voellmy R. 1998. Repression of heat shock transcription factor HSF1 activation by HSP90 (HSP90 complex) that forms a stress-sensitive complex with HSF1. Cell 94, 471-480.

\section{Figure legends}




\section{Fig. 1. SUMO and SUMO2 combined are essential for Arabidopsis to sustain} elevated temperatures.

A. Growth phenotype of the indicated plant genotypes at different temperatures to assess suppression of SNC1-dependent autoimmunity at $28^{\circ} \mathrm{C}$. bon1 and srfr1-4 are two mutants with SNC1-dependent autoimmunity. Plant age is indicated on the left (w, weeks). Images on the right show the rosette phenotype of sumo1-1;SUMO2 ${ }^{K D}$ at 25 vs. $28^{\circ} \mathrm{C}$. WT, wildtype accession Col-0.

B. Growth phenotype at $22 / 28^{\circ} \mathrm{C}$ for the single mutants sumo1-1, sumo2-1 and SUMO2 ${ }^{K D}$ (line B) and the corresponding double mutant sumo1-1;SUMO2 ${ }^{K D}$. Picture was taken four weeks after germination.

C. Premature collapse of sumo1-1;SUMO2 $2^{K D}$ at $28^{\circ} \mathrm{C}$ (bottom) is independent of EDS1, PAD4, or SA accumulation. At $22^{\circ} \mathrm{C}$ (top), the rosette morphology sumo1$1 ;$ SUMO2 ${ }^{K D}$ was partially recovered in the eds1-2, pad4-2, sid2-1 backgrounds.

Picture was taken five weeks post germination.

D. Immunoblot showing PR1 and PR2 protein levels in 5-week-old plants. PR1 and PR2 levels were suppressed when sumo1-1;SUMO2 ${ }^{K D}$ is introduced in the pad4-1, eds 1-2 or sid2-1 backgrounds.

E. Null mutant of the SUMO E3 ligases SIZ1 and HPY2 survive at $28^{\circ} \mathrm{C}(\mathbf{E} .1$, zoom of hpy2-2 rosette).

F. Null mutant of the SUMO protease ESD4 (esd4-1) survives at $28^{\circ} \mathrm{C}(\mathbf{F . 1}$, zoom of esd4-1 rosette).

Fig. 2. An incubation period of at least one week at $28^{\circ} \mathrm{C}$ results in thermolethality of sumo1-1;SUMO2 ${ }^{K D}$.

A. Diagram depicting the experimental procedure shown in (B). Following germination at $22^{\circ} \mathrm{C}$, plants were transferred to $28^{\circ} \mathrm{C}$ after 1,2 , or 3 weeks. Control plants remained at 22 or $28^{\circ} \mathrm{C}$ constant temperature for four weeks.

B. Growth of sumo1-1;SUMO2 $2^{K D}$ for 1 week at $22^{\circ} \mathrm{C}$ is enough to prevent collapse during an additional 3 weeks at $28^{\circ} \mathrm{C}$ (B.1, zoom), while eTK still collapsed even when it only experienced the final week at $28^{\circ} \mathrm{C}$. bon 1 was included as a control for the temperature-sensitive recovery of the growth phenotype. Picture was taken four weeks post germination ( $n=8$ plants per line per treatment). 
C. Similar to $(A)$, except that plants were germinated at $28^{\circ} \mathrm{C}$ and then transferred to $22^{\circ} \mathrm{C}$.

D. The same experiment as $(\mathrm{B})$, except that it started at $28^{\circ} \mathrm{C}$. The mutant sumo1$1 ;$ SUMO2 $2^{K D}$ survived its first week at $28^{\circ} \mathrm{C}$ ( $\mathrm{n}=3$ of 24 plants), while eTK does not germinate at $28^{\circ} \mathrm{C}$ (see also Fig. $6 \mathrm{~A}$ ). bon1 showed progressive recovery with increasing time spend at $28^{\circ} \mathrm{C}$.

E. Bar graph showing the proportion of surviving seedlings (\%) of sumo1-1;SUMO2 $2^{K D}$ in response to an initial growth phase at $28^{\circ} \mathrm{C}$ (days) followed by a shift to $22^{\circ} \mathrm{C}$ at the indicated day. The plants were scored after four weeks $(n=28)$.

\section{Fig. 3. One week at $28^{\circ} \mathrm{C}$ results in sustained arrested development of sumo1-} 1;SUMO2 ${ }^{K D}$ culminating in rosette senescence and lethality.

A. Diagram depicting the experimental procedure. Two weeks post germination eight plants per genotype were shifted to $28^{\circ} \mathrm{C}$ for a period of $2-14$ days, after which they received a cooler temperature regime $\left(22^{\circ} \mathrm{C}\right)$ for another 4-6 weeks. Their development was weekly assessed starting when they were four-weeks old.

B. Rosette development of sumo1-1;SUMO2 ${ }^{K D}$ was arrested while eTK rapidly collapsed when these genotypes received a ten-day period at $28^{\circ} \mathrm{C}$, but not for a sixday period. The pictures show the same plants in time (weeks) after they had experienced a brief warm period of six or ten days.

C. Zoom of 8-weeks-old sumo1-1;SUMO2 $2^{K D}$ plant that received 10 days at $28^{\circ} \mathrm{C}$. The rosette stopped developing and the leaves turn eventually necrotic, while the shoot apical meristem develops a tiny, distorted inflorescence with maximum four flowers.

D. Image depicting 7-weeks-old plants for five genotypes (left) after receiving different temperature regimes (top). Growth of both bon1 and siz1-2 recovered partially in response to the $28^{\circ} \mathrm{C}$ period. In contrast, eTK collapsed and sumo1$1 ;$ SUMO2 ${ }^{K D}$ showed arrested development after 10 or more days at $28^{\circ} \mathrm{C}$. For each combination 8 plants were assessed and the experiment was repeated twice with a similar result. Plants in the white boxes are depicted in (B).

Fig. 4. Shoot apical meristem of sumo1-1;SUMO2 $2^{K D}$ collapses at $28^{\circ} \mathrm{C}$ without recovery upon return to $22^{\circ} \mathrm{C}$. 
A. Diagram depicting the different temperature regimes (black circles) shown in (BD).

B. Cryo-scanning electron microscopy image of the rosette apical meristem (AM) of 24- or 31-day-old plants after exposure to the temperature regimes depicted in (A). The corresponding rosette is displayed on the right. Asterisks $\left(^{*}\right)$ marks newly formed leaves upon return to $22^{\circ} \mathrm{C}$ (without thermomorphogenesis response). $\mathrm{FB}$, floral buds in a bolted rosette. Red arrows highlight the disorganized tissue structure with malformations. For each line and condition at least 8 meristems were inspected with the SEM and the experiment was repeated three times with similar result. WT (Col$0)$; wildtype background.

C. Direct germination at $28^{\circ} \mathrm{C}$ caused seedling lethality of sumo1-1;SUMO2 $2^{K D}$ after 24 days, which prevented the SEM analysis.

D. Same as B, except that the rosette apical meristem of $e T K$ and siz1-2 is shown. The SEM of $e T K$ was already inspected after 4 days at $28^{\circ} \mathrm{C}$, as after this stage dissecting of the SEM was practically impossible.

Fig. 5. Architecture of the lateral root primordia of sumo1-1;SUMO2 ${ }^{K D}$ is disturbed in response to high ambient temperatures.

A. Bar graph depicting the average length ( $\pm S E)$ of the primary root of the genotypes Col-0, sumo1-1;SUMO2 $2^{K D}$ and $e T K 12$ days post germination at $22^{\circ} \mathrm{C}$ or $28^{\circ} \mathrm{C}$. All plants were germinated and grown for 4 days at $22^{\circ} \mathrm{C}$ before transferred to new plates for another 8 days at either $22^{\circ} \mathrm{C}, 28^{\circ} \mathrm{C}$, or 3 days at $22^{\circ} \mathrm{C}$ followed by $28^{\circ} \mathrm{C}$ for 5 days $(22 \mathrm{C}>28 \mathrm{C})$. In total, the length of approximately 40 roots was measured per line for each temperature regime. Brackets display the result of an ANOVA statistical test followed by Tukey multiple comparison test. Significance results are only shown between the mutants and the wild type control (Col-0) (NS, not significant; * $p<0.05$, $\left.{ }^{* * *} \mathrm{p}<0.001,{ }^{* * * *} \mathrm{p}<0.0001\right)$.

B. Similar to $(\mathbf{A})$, except that the average number of lateral roots was determined.

C. Propidium iodide staining showing the architecture of lateral root primordia (LR) and the primary root tip (PR) of 12 to 14-day old seedlings of wildtype (WT) plants (Col-0) and sumo1-1; SUMO2 ${ }^{K D}$ in response to a temperature regime of $22^{\circ} \mathrm{C}$ or $28^{\circ} \mathrm{C}$ (experiment was repeated three times with similar results, per condition at least 5 roots were inspected for each experiment). 


\section{Fig. 6. sumo1-1;SUMO2 ${ }^{K D}$ displays a normal acquired heat stress and}

\section{thermotolerance response.}

A. Heat-sensitive phenotype of wildtype (WT Col-0), siz1-2, sumo1-1;SUMO2 ${ }^{K D}$ and eTK (HsfA1a,b,d) seedlings in response to different heat shock (HS) regimes (shown at the top). Plants were pre-grown at $22^{\circ} \mathrm{C}$ for 14 days prior to the treatment indicated. Phenotype of $e T K$ is shown as it lacks SAT and LAT. Whereas a single treatment at $44^{\circ} \mathrm{C}$ for 50 min is sufficient to kill Arabidopsis, WT plants, siz1 and sumo1-1;SUMO2 ${ }^{K D}$ show normal acclimation when pre-treated at $37^{\circ} \mathrm{C}$ for $60 \mathrm{~min}$. Experiment was repeated three times with similar result.

B. Immunoblot showing the conjugated and free SUMO1/2, SIZ1, HSP70, HSP90, and HSP101 protein levels in seedlings (WT Col-0, siz1-2, sumo1-1;SUMO2 ${ }^{K D}$ and eTK) after $30-\mathrm{min}$ heat stress at $37^{\circ} \mathrm{C}$. After a one-hour recovery period, the total protein fraction was extracted. Seedlings were pre-grown for 14 days at $22^{\circ} \mathrm{C}$. Ponceau $S$ is shown as a control for equal protein loading.

C. Immunoblot showing the conjugated/free SUMO1/2 levels, HSP90, HSP101, and HSFA2 levels in seedlings pre-grown at $22^{\circ} \mathrm{C}$ on plates $(0 \mathrm{hrs})$ and then shifted to $28^{\circ} \mathrm{C}$ (4 hours or 7 days). Other growth conditions similar to (B). eTK samples at 7 days (7d) were not included, as they had collapsed preventing any protein isolation. Ponceau $\mathrm{S}$ is shown as a control for equal protein loading.

\section{Fig 7. Transcriptional response of sumo1-1;SUMO2 ${ }^{K D}$ and $e T K$ differs in} response to a sustained warm period at 28 degrees Celsius.

A. Venn diagrams showing the total number of differentially expressed genes (DEGs) detected at the different time points for each genotype (compared to pad4-1) and their overlap. The overlap in the transcriptional response after 24 hours at $28^{\circ} \mathrm{C}$ between sumo1/2 ${ }^{K D} ;$ pad4 and siz1;pad4 is largely due to a delayed thermomorphogenesis response in both plant lines (Hammoudi et al., 2018). All DEGs passed a FDR of $q$-value $<0.01$.

B. Principal component analysis (PCA) of DEGs detected showing that $e T K$ responds distinct from both SUMO-deficient mutants (sumo1/2KD;pad4 and siz1;pad4and the control (pad4-1) ( $n=3$ for each genotype/time point). 
C. Dot plot depicting enriched gene ontology (GO) terms for the top 500 DEGs (either overexpressed or downregulated) that contribute to the loading of the principal component $(\mathrm{PC})$ axes shown in panel $\mathrm{B}$. Dot size indicates the $\mathrm{k} / \mathrm{n}$ ratio ("gene ratio"), where $k$ is the number of genes participating in this GO term, and $n$ is the total number of genes annotated for this GO term in the genome. Dot color indicates the adjusted $p$-value of the enrichment test (hypergeometry test with Yekutieli FDR correction, Padj <0.01). GO terms shown were manually selected to best represent the biological processes impacted for interdependent GO-terms. 


\section{Figure 1}

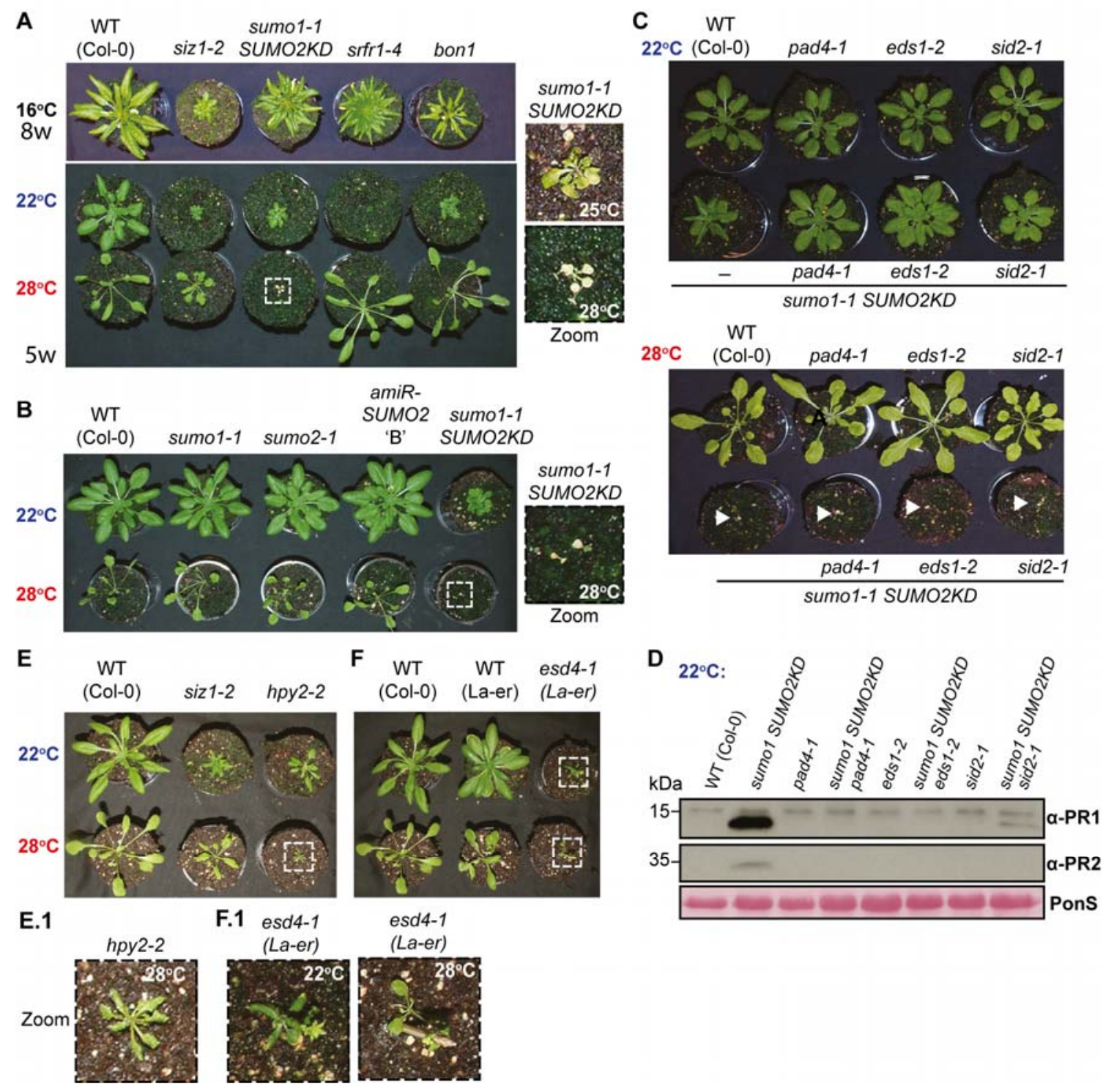

Fig. 1. SUMO and SUMO2 combined are essential for Arabidopsis to sustain elevated temperatures.

A. Growth phenotype of the indicated plant genotypes at different temperatures to assess suppression of SNC1-dependent autoimmunity at $28^{\circ} \mathrm{C}$. bon1 and srfr1-4 are two mutants with SNC1-dependent autoimmunity. Plant age is indicated on the left ( $w$, weeks). Images on the right show the rosette phenotype of sumo1-1;SUMO2 $2^{K D}$ at 25 vs. $28^{\circ} \mathrm{C}$. WT, wildtype accession Col-0.

B. Growth phenotype at $22 / 28^{\circ} \mathrm{C}$ for the single mutants sumo1-1, sumo2-1 and $S U M O 2^{K D}$ (line B) and the corresponding double mutant sumo1-1;SUMO2 ${ }^{K D}$. Picture was taken four weeks after germination. C. Premature collapse of sumo1-1;SUMO $2^{K D}$ at $28^{\circ} \mathrm{C}$ (bottom) is independent of EDS1, PAD4, or SA accumulation. At $22^{\circ} \mathrm{C}$ (top), the rosette morphology sumo1-1;SUMO $2^{K D}$ was partially recovered in the eds1-2, pad4-2, sid2-1 backgrounds. Picture was taken five weeks post germination.

D. Immunoblot showing PR1 and PR2 protein levels in 5-week-old plants. PR1 and PR2 levels were suppressed when sumo1-1;SUMO2 ${ }^{K D}$ is introduced in the pad4-1, eds1-2 or sid2-1 backgrounds.

E. Null mutant of the SUMO E3 ligases SIZ1 and HPY2 survive at $28^{\circ} \mathrm{C}$ (E.1, zoom of hpy2-2 rosette). F. Null mutant of the SUMO protease ESD4 (esd4-1) survives at $28^{\circ} \mathrm{C}$ (F.1, zoom of esd4-1 rosette). 


\section{Figure 2}

A

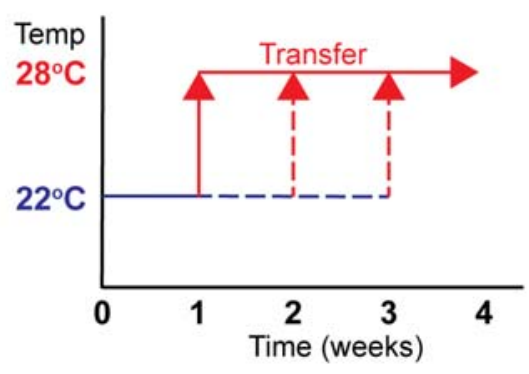

B.1
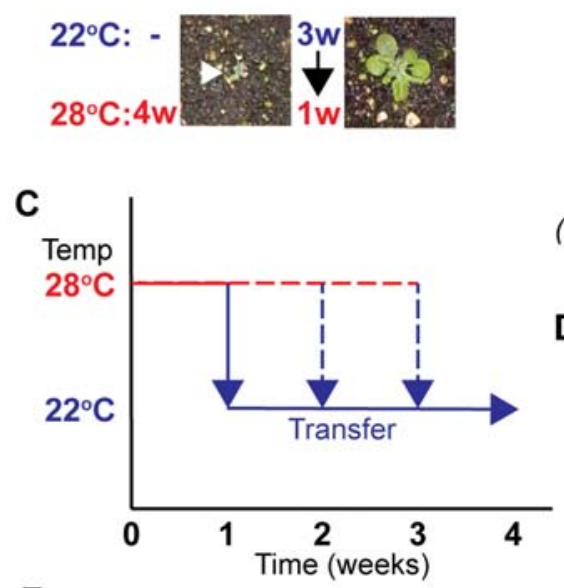

E

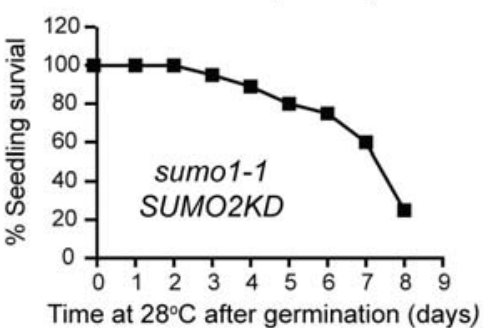

B
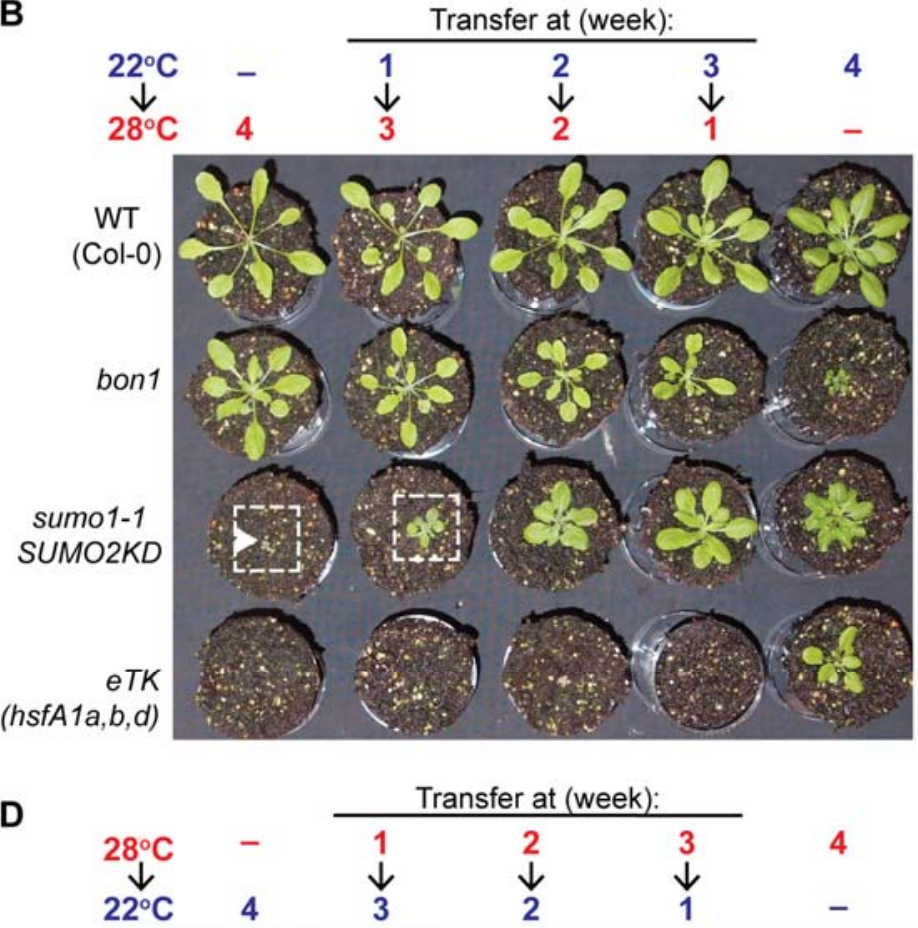

sumo1-1

SUMO2KD

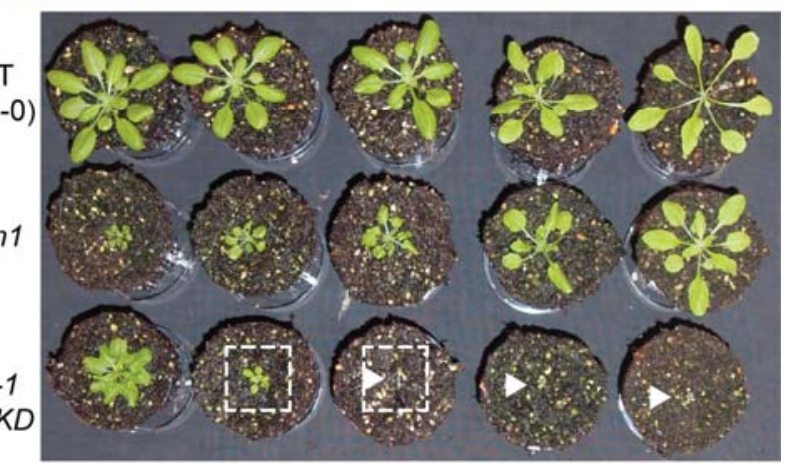

Fig. 2. An incubation period of at least one week at $28^{\circ} \mathrm{C}$ results in thermo-lethality of sumo11;SUMO2 ${ }^{K D}$.

A. Diagram depicting the experimental procedure shown in (B). Following germination at $22^{\circ} \mathrm{C}$, plants were transferred to $28^{\circ} \mathrm{C}$ after 1,2 , or 3 weeks. Control plants remained at 22 or $28^{\circ} \mathrm{C}$ constant temperature for four weeks.

B. Growth of sumo 1-1;SUMO2 $2^{K D}$ for 1 week at $22^{\circ} \mathrm{C}$ is enough to prevent collapse during an additional 3 weeks at $28^{\circ} \mathrm{C}$ (B.1, zoom), while $e T K$ still collapsed even when it only experienced the final week at $28^{\circ} \mathrm{C}$. bon 1 was included as a control for the temperature-sensitive recovery of the growth phenotype.

Picture was taken four weeks post germination ( $n=8$ plants per line per treatment).

C. Similar to $(A)$, except that plants were germinated at $28^{\circ} \mathrm{C}$ and then transferred to $22^{\circ} \mathrm{C}$.

D. The same experiment as (B), except that it started at $28^{\circ} \mathrm{C}$. The mutant sumo1-1;SUMO2 ${ }^{K D}$ survived its first week at $28^{\circ} \mathrm{C}$ ( $\mathrm{n}=3$ of 24 plants), while $e T K$ does not germinate at $28^{\circ} \mathrm{C}$ (see also Fig. $6 \mathrm{~A}$ ). bon 1 showed progressive recovery with increasing time spend at $28^{\circ} \mathrm{C}$.

E. Bar graph showing the proportion of surviving seedlings (\%) of sumo1-1;SUMO2 ${ }^{K D}$ in response to an initial growth phase at $28^{\circ} \mathrm{C}$ (days) followed by a shift to $22^{\circ} \mathrm{C}$ at the indicated day. The plants were scored after four weeks $(n=28)$. 


\section{Figure 3}
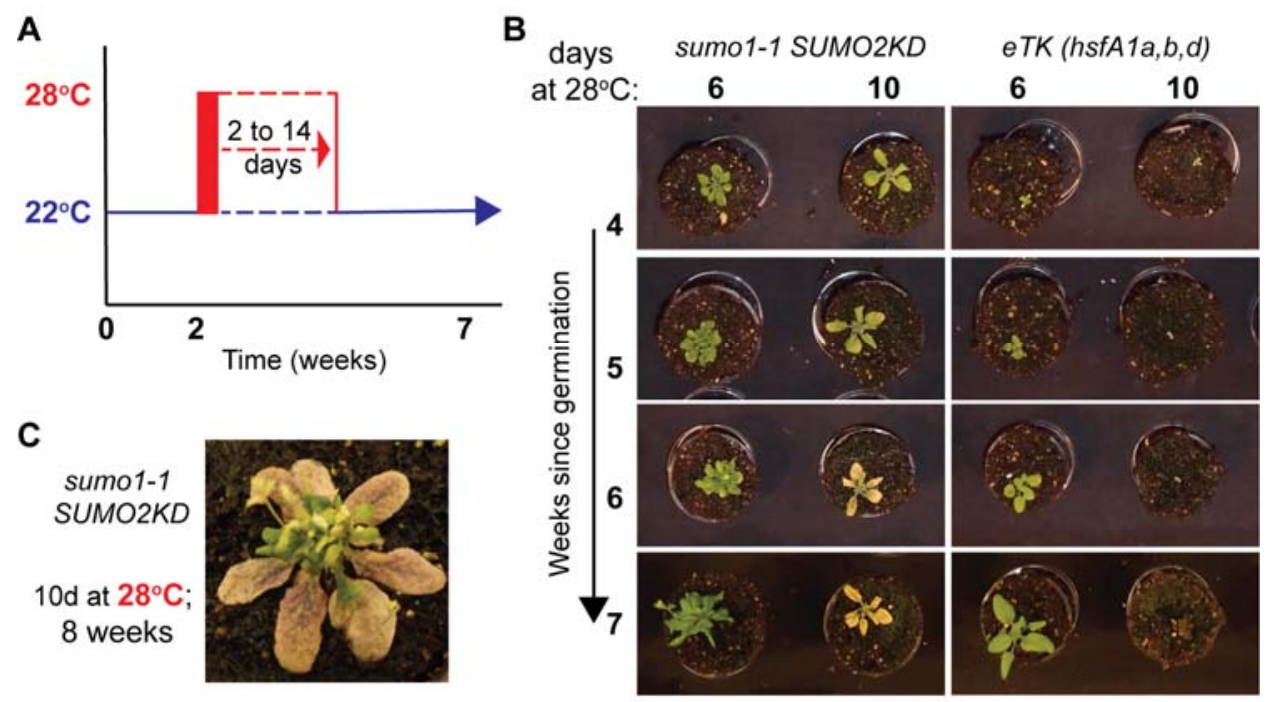

D

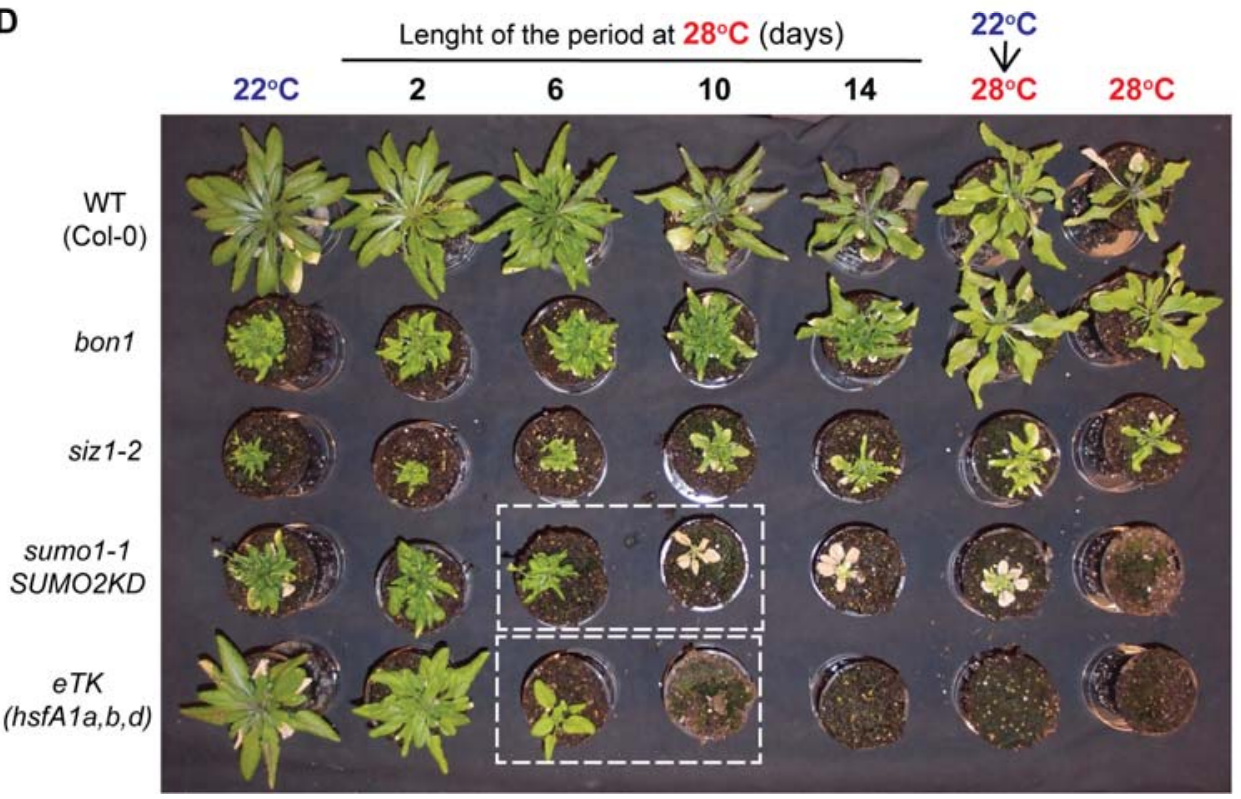

Fig. 3. One week at $28^{\circ} \mathrm{C}$ results in sustained arrested development of sumo1-1;SUMO2 ${ }^{K D}$ culminating in rosette senescence and lethality.

A. Diagram depicting the experimental procedure. Two weeks post germination eight plants per genotype were shifted to $28^{\circ} \mathrm{C}$ for a period of 2-14 days, after which they received a cooler temperature regime $\left(22^{\circ} \mathrm{C}\right)$ for another $4-6$ weeks. Their development was weekly assessed starting when they were four-weeks old.

B. Rosette development of sumo1-1;SUMO2 ${ }^{K D}$ was arrested while eTK rapidly collapsed when these genotypes received a ten-day period at $28^{\circ} \mathrm{C}$, but not for a six-day period. The pictures show the same plants in time (weeks) after they had experienced a brief warm period of six or ten days.

C. Zoom of 8-weeks-old sumo1-1;SUMO2 ${ }^{K D}$ plant that received 10 days at $28^{\circ} \mathrm{C}$. The rosette stopped developing and the leaves turn eventually necrotic, while the shoot apical meristem develops a tiny, distorted inflorescence with maximum four flowers.

D. Image depicting 7-weeks-old plants for five genotypes (left) after receiving different temperature regimes (top). Growth of both bon 1 and $\operatorname{siz} 1-2$ recovered partially in response to the $28^{\circ} \mathrm{C}$ period. In contrast, eTK collapsed and sumo1-1;SUMO2 ${ }^{K D}$ showed arrested development after 10 or more days at $28^{\circ} \mathrm{C}$. For each combination 8 plants were assessed and the experiment was repeated twice with a similar result. Plants in the white boxes are depicted in (B). 
Figure 4

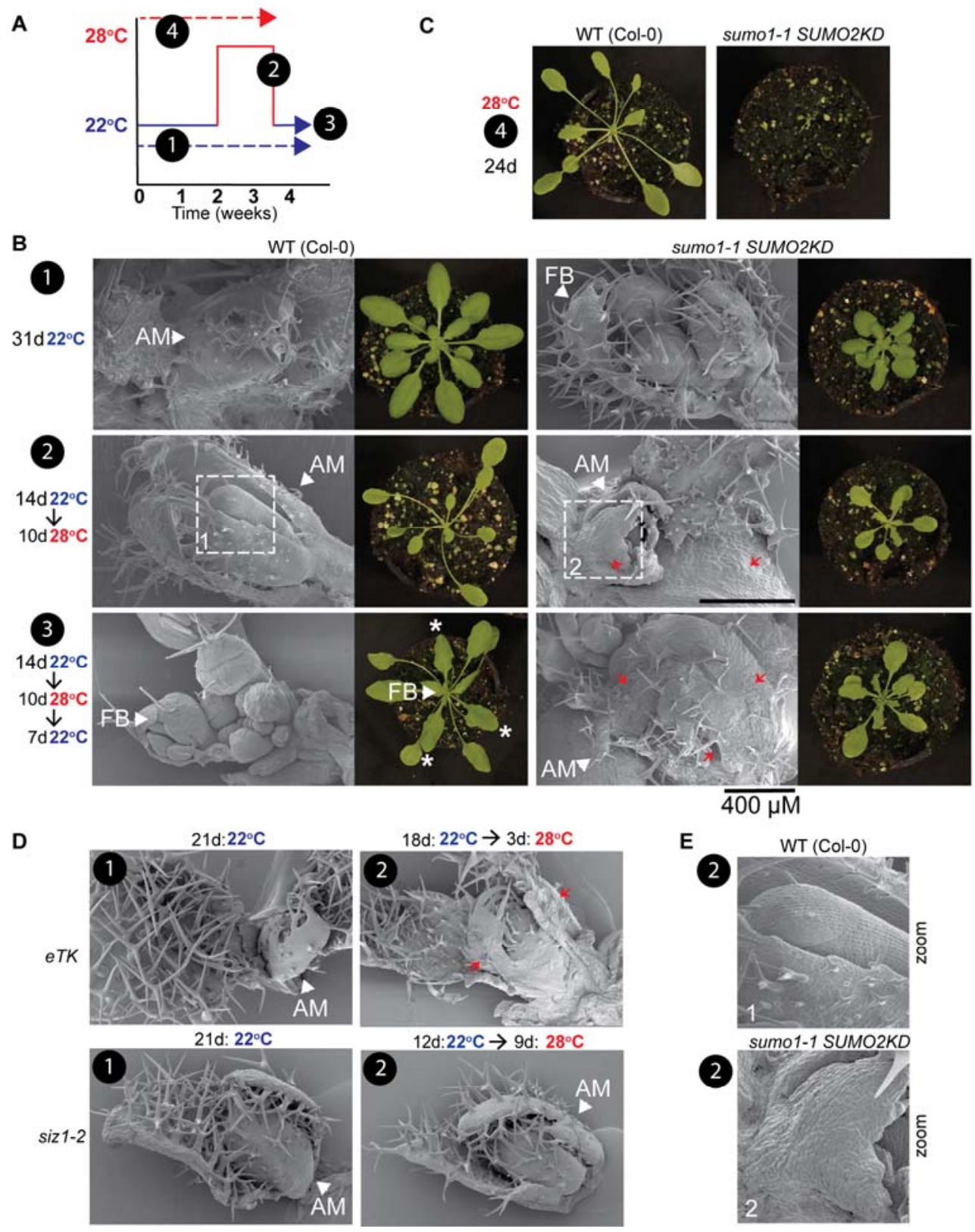

Fig. 4. Shoot apical meristem of sumo1-1;SUMO2 ${ }^{K D}$ collapses at $28^{\circ} \mathrm{C}$ without recovery upon return to $22^{\circ} \mathrm{C}$.

A. Diagram depicting the different temperature regimes (black circles) shown in (B-D).

B. Cryo-scanning electron microscopy image of the rosette apical meristem (AM) of 24- or 31-day-old plants after exposure to the temperature regimes depicted in (A). The corresponding rosette is displayed on the right. Asterisks $\left({ }^{*}\right)$ marks newly formed leaves upon return to $22^{\circ} \mathrm{C}$ (without thermomorphogenesis response). FB, floral buds in a bolted rosette. Red arrows highlight the disorganized tissue structure with malformations. For each line and condition at least 8 meristems were inspected with the SEM and the experiment was repeated three times with similar result. WT (Col-0); wildtype background.

C. Direct germination at $28^{\circ} \mathrm{C}$ caused seedling lethality of sumo1-1;SUMO2 ${ }^{K D}$ after 24 days, which prevented the SEM analysis.

D. Same as B, except that the rosette apical meristem of eTK and siz1-2 is shown. The SEM of $e T K$ was already inspected after 4 days at $28^{\circ} \mathrm{C}$, as after this stage dissecting of the SEM was practically impossible. 


\section{Figure 5}

A

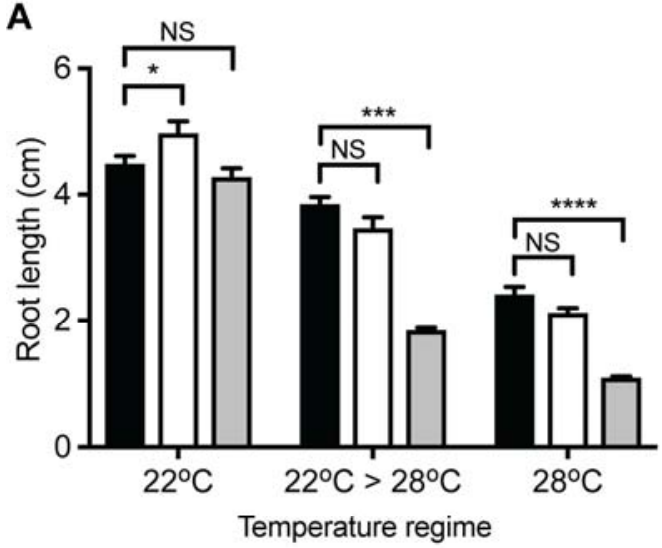

C
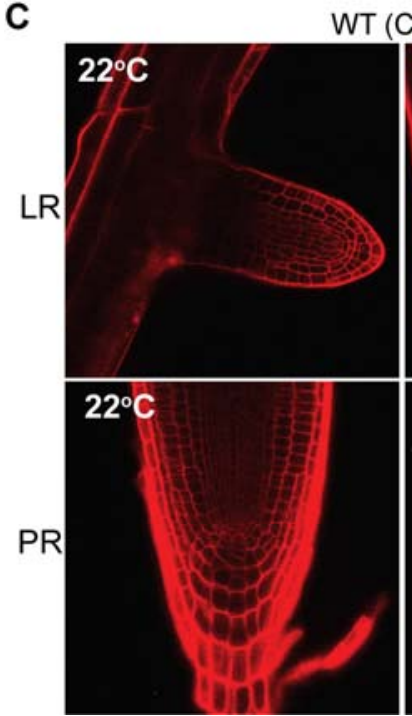
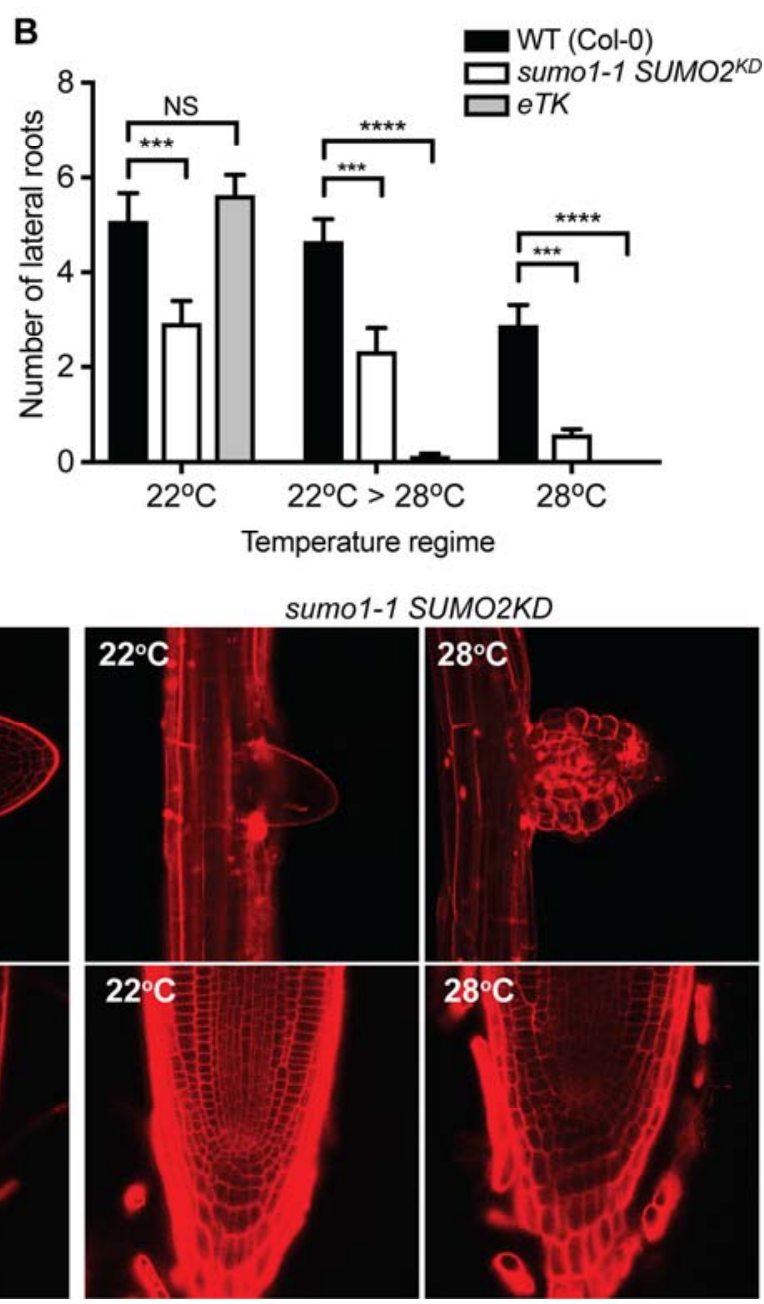

Fig. 5. Architecture of the lateral root primordia of sumo1-1;SUMO2 ${ }^{K D}$ is disturbed in response to high ambient temperatures.

A. Bar graph depicting the average length ( $\pm S E$ ) of the primary root of the genotypes Col-0, sumo1$1 ;$ SUMO2 $2^{K D}$ and $e T K 12$ days post germination at $22^{\circ} \mathrm{C}$ or $28^{\circ} \mathrm{C}$. All plants were germinated and grown for 4 days at $22^{\circ} \mathrm{C}$ before transferred to new plates for another 8 days at either $22^{\circ} \mathrm{C}, 28^{\circ} \mathrm{C}$, or 3 days at $22^{\circ} \mathrm{C}$ followed by $28^{\circ} \mathrm{C}$ for 5 days $(22 \mathrm{C}>28 \mathrm{C})$. In total, the length of approximately 40 roots was measured per line for each temperature regime. Brackets display the result of an ANOVA statistical test followed by Tukey multiple comparison test. Significance results are only shown between the mutants and the wild type control (Col-0) (NS, not significant; ${ }^{*}, p<0.05,{ }^{\star \star \star} p<0.001,{ }^{* \star \star \star}$ $\mathrm{p}<0.0001)$.

B. Similar to (A), except that the average number of lateral roots was determined.

C. Propidium iodide staining showing the architecture of lateral root primordia (LR) and the primary root tip (PR) of 12 to 14-day old seedlings of wildtype (WT) plants (Col-0) and sumo1-1;SUMO2 ${ }^{K D}$ in response to a temperature regime of $22^{\circ} \mathrm{C}$ or $28^{\circ} \mathrm{C}$ (experiment was repeated three times with similar results, per condition at least 5 roots were inspected for each experiment). 


\section{Figure 6}
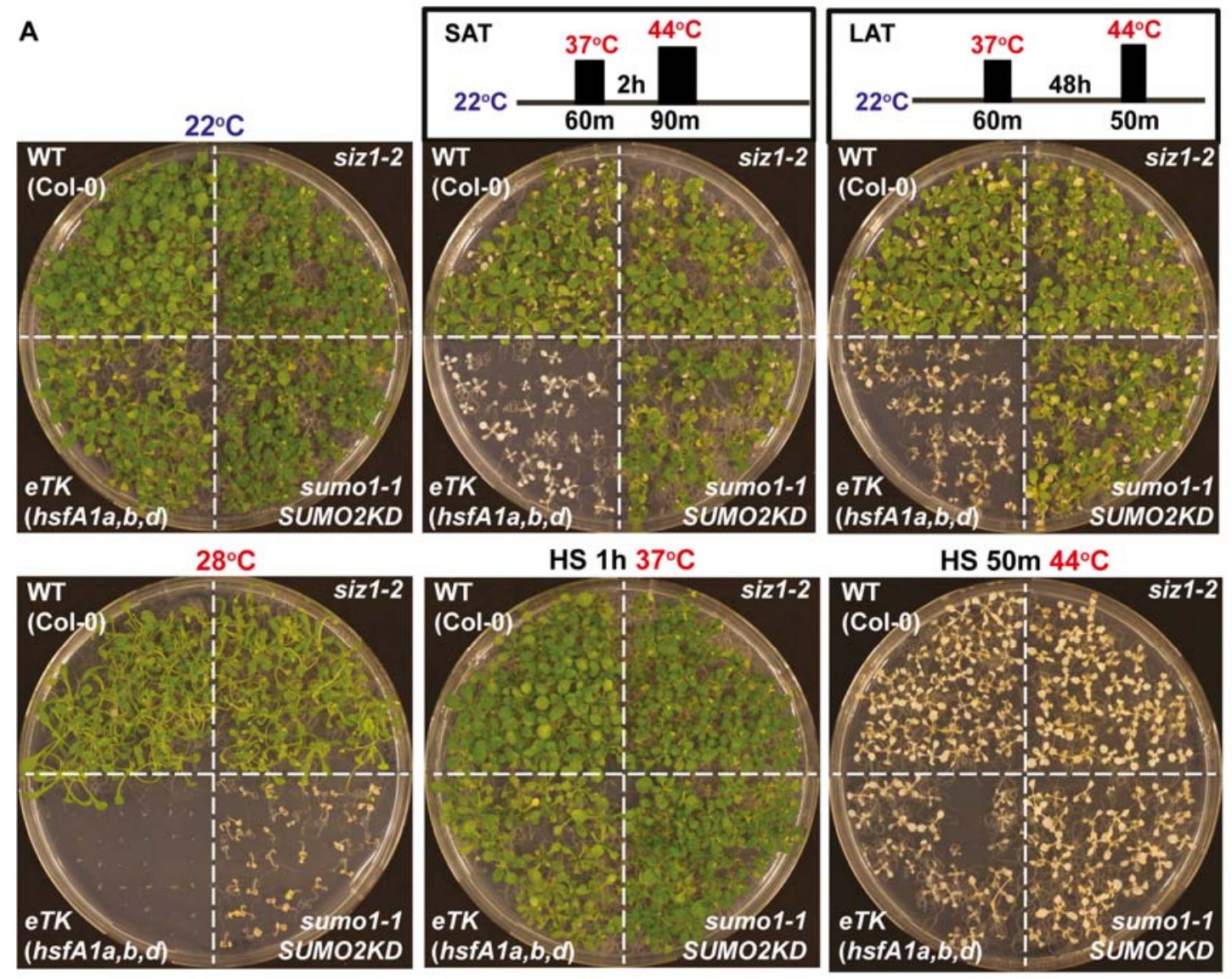

HS $1 \mathrm{~h} 37^{\circ} \mathrm{C}$

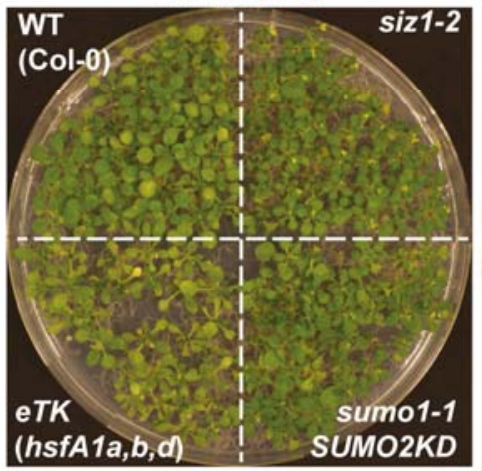

HS $50 \mathrm{~m} 44^{\circ} \mathrm{C}$

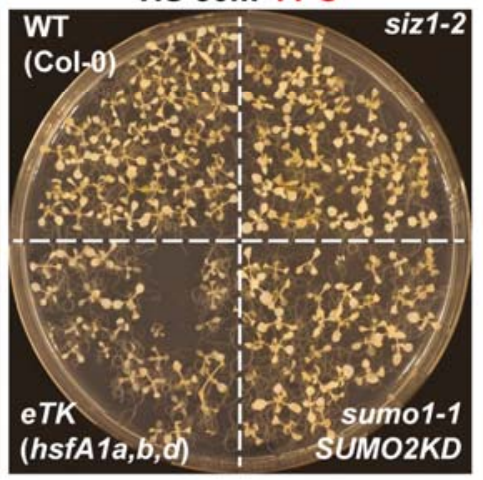

B

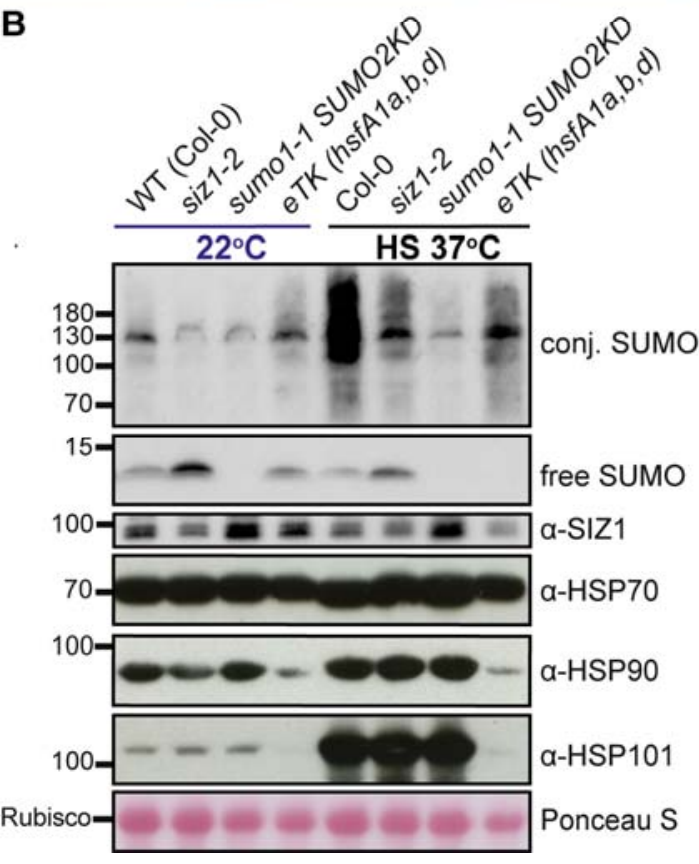

C

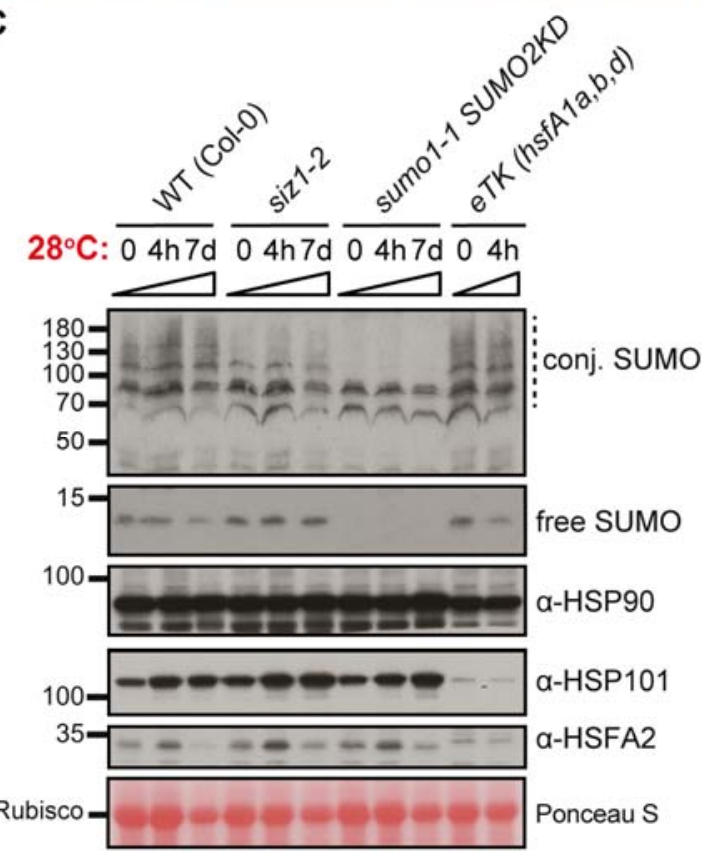


bioRxiv preprint doi: https://doi.org/10.1101/2021.02.04.429700; this version posted February 4, 2021. The copyright holder for this preprint (which was not certified by peer review) is the author/funder, who has granted bioRxiv a license to display the preprint in perpetuity. It is made available under aCC-BY-NC-ND 4.0 International license.

Fig. 6. sumo1-1;SUMO2 ${ }^{K D}$ displays a normal acquired heat stress and thermotolerance response.

A. Heat-sensitive phenotype of wildtype (WT Col-0), siz1-2, sumo1-1;SUMO2 ${ }^{K D}$ and eTK (HsfA1a,b,d) seedlings in response to different heat shock (HS) regimes (shown at the top). Plants were pre-grown at $22^{\circ} \mathrm{C}$ for 14 days prior to the treatment indicated. Phenotype of eTK is shown as it lacks SAT and LAT. Whereas a single treatment at $44^{\circ} \mathrm{C}$ for 50 min is sufficient to kill Arabidopsis, WT plants, siz 1 and sumo1-1;SUMO2 ${ }^{K D}$ show normal acclimation when pre-treated at $37^{\circ} \mathrm{C}$ for $60 \mathrm{~min}$. Experiment was repeated three times with similar result.

B. Immunoblot showing the conjugated and free SUMO1/2, SIZ1, HSP70, HSP90, and HSP101 protein levels in seedlings (WT Col-0, siz1-2, sumo1-1;SUMO2 ${ }^{K D}$ and eTK) after 30-min heat stress at $37^{\circ} \mathrm{C}$. After a one-hour recovery period, the total protein fraction was extracted. Seedlings were pregrown for 14 days at $22^{\circ} \mathrm{C}$. Ponceau $S$ is shown as a control for equal protein loading.

C. Immunoblot showing the conjugated/free SUMO1/2 levels, HSP90, HSP101, and HSFA2 levels in seedlings pre-grown at $22^{\circ} \mathrm{C}$ on plates $(0 \mathrm{hrs})$ and then shifted to $28^{\circ} \mathrm{C}$ ( 4 hours or 7 days). Other growth conditions similar to (B). eTK samples at 7 days (7d) were not included, as they had collapsed preventing any protein isolation. Ponceau $S$ is shown as a control for equal protein loading. 
bioRxiv preprint doi: https://doi org/10.1101/2021.02.04.429700; this version posted February 4, 2021. The copyright holder for this preprint (which was not certified by peer review) is the author/funder, who has granted bioRxiv a license to display the preprint in perpetuity. It is made available under aCC-BY-NC-ND 4.0 International license.

\section{Figure 7}

A $22^{\circ} \mathrm{C}$

$28^{\circ} \mathrm{C}(24 \mathrm{~h})$

$28^{\circ} \mathrm{C}(96 \mathrm{~h})$

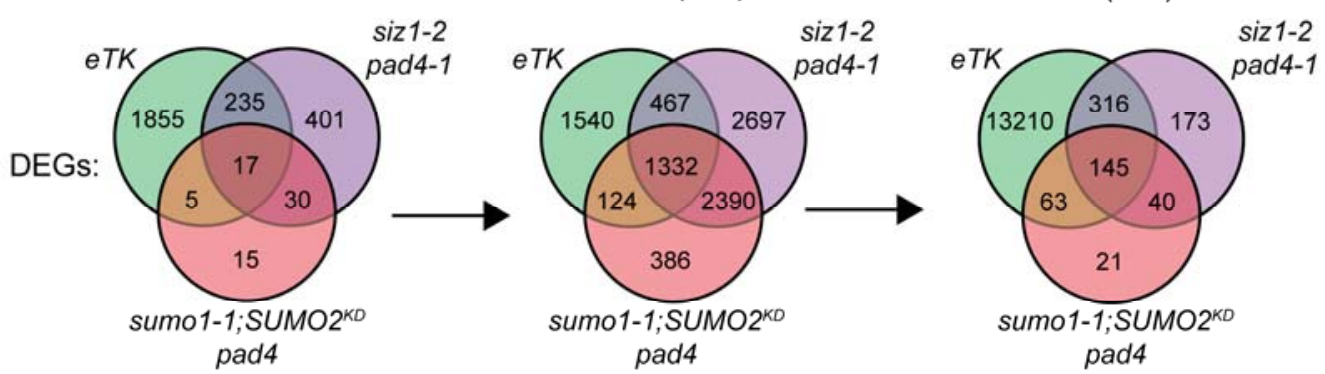

B

$22^{\circ} \mathrm{C}$
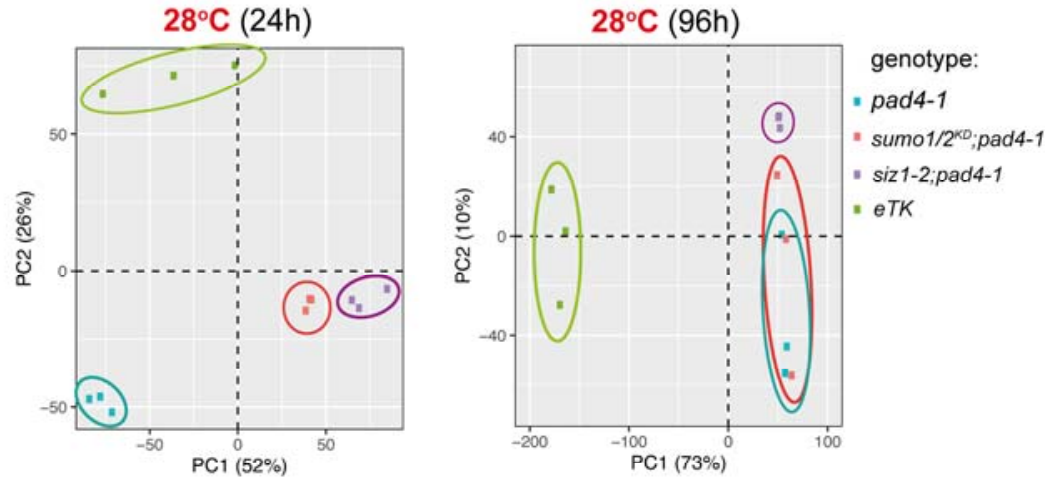

C

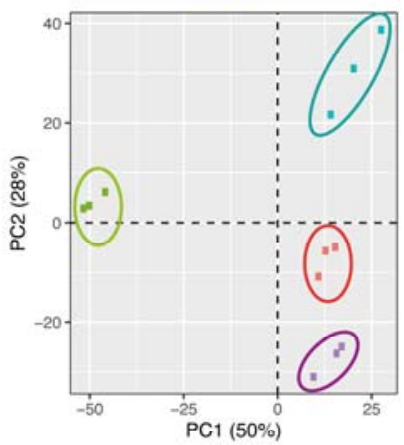

GO term:

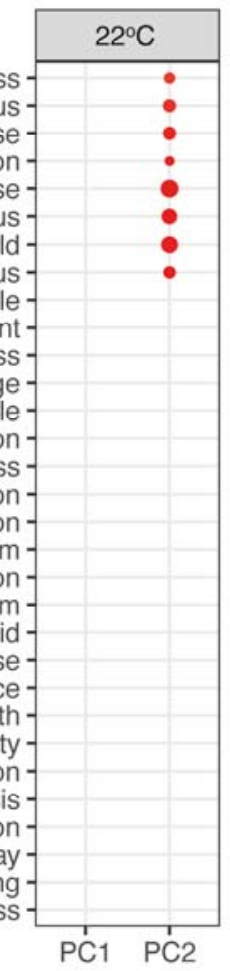
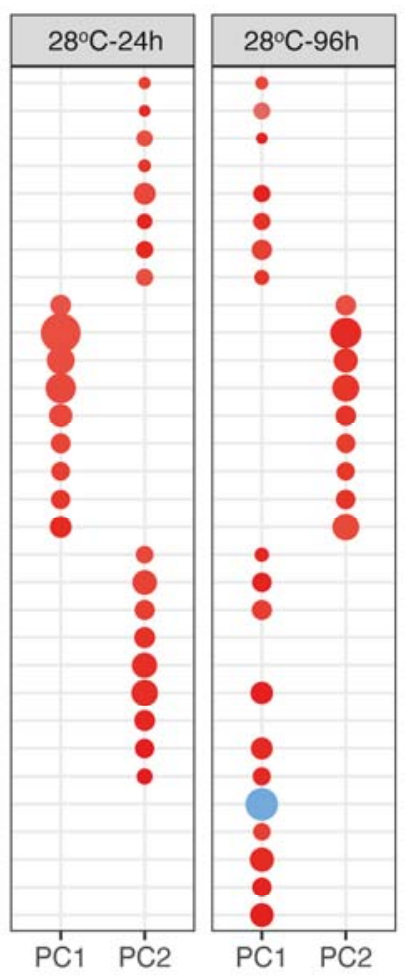

$-\log 10 P_{\text {adj }}$

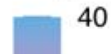

30

20

10

chromosome organizat

DNA metabolic process cell division DNA replication

defense response to other organism defense response, incompatible interaction defense response to bacterium response to salicylic acid plant-type hypersensitive response systemic acquired resistance programmed cell death response to light intensity response to water deprivation photosynthesis response to radiation auxin-activated signaling pathway toxin metabolic process$$
\text { PC1 PC2 }
$$$$
\text { PC1 PC2 }
$$

\section{GeneRatio}

- 0.1

0.2

0.3 
bioRxiv preprint doi: https://doi.org/10.1101/2021.02.04.429700; this version posted February 4, 2021. The copyright holder for this preprint (which was not certified by peer review) is the author/funder, who has granted bioRxiv a license to display the preprint in perpetuity. It is made available under aCC-BY-NC-ND 4.0 International license.

Fig 7. Transcriptional response of sUmo1-1;SUMO ${ }^{K D}$ and $e T K$ differs in response to a sustained warm period at 28 degrees Celsius.

A. Venn diagrams showing the total number of differentially expressed genes (DEGs) detected at the different time points for each genotype (compared to pad4-1) and their overlap. The overlap in the transcriptional response after 24 hours at $28^{\circ} \mathrm{C}$ between sumo $1 / 2^{K D} ;$ pad 4 and siz1;pad 4 is largely due to a delayed thermomorphogenesis response in both plant lines (Hammoudi et al., 2018). All DEGs passed a FDR of $q$-value $<0.01$.

B. Principal component analysis (PCA) of DEGs detected showing that $e T K$ responds distinct from both SUMO-deficient mutants (sumo1/2 ${ }^{K D}$;pad4 and siz1;pad4and the control (pad4-1) ( $\mathrm{n}=3$ for each genotype/time point).

C. Dot plot depicting enriched gene ontology (GO) terms for the top 500 DEGs (either overexpressed or downregulated) that contribute to the loading of the principal component (PC) axes shown in panel B. Dot size indicates the $k / n$ ratio ("gene ratio"), where $k$ is the number of genes participating in this GO term, and $n$ is the total number of genes annotated for this GO term in the genome. Dot color indicates the adjusted $p$-value of the enrichment test (hypergeometry test with Yekutieli FDR correction, Padj <0.01). GO terms shown were manually selected to best represent the biological processes impacted for interdependent GO-terms. 